\title{
Trends in Archaeological Simulation
}

\author{
M. W. Lake
}

Published online: 7 November 2013

(C) The Author(s) 2013. This article is published with open access at Springerlink.com

\begin{abstract}
This paper provides an up-to-date history of archaeological computer simulation, starting with the early 1970 s simulation models, but paying particular attention to those developed over the past 20-25 years. It revises earlier accounts of archaeological simulation by proposing an alternation between programmatic phases, in which published work tends to be about simulation as a method, and mature phases in which there is greater emphasis on the substantive results of simulation experiments. The paper concludes that the burgeoning interest in computer simulation since circa 2000 is largely characterized by mature application in areas where it fits naturally into existing inferential frameworks (e.g., certain strands of evolutionary archaeology) but that explicitly "sociological" simulation remains a challenge.
\end{abstract}

Keywords Computer simulation · Agent-based modelling · Dynamical systems · Archaeological theory · Quantitative methods · Evolutionary archaeology · Human ecodynamics

\section{Introduction}

This paper updates the published history of archaeological computer simulation (Doran and Hodson 1975; Bell 1987; Aldenderfer 1991; Mithen 1994; Lake 2001a; McGlade 2005) to take account of developments over the past 15 years and with the benefit of greater hindsight on the 1990s. The principal aim is to provide the reader with a comprehensive survey of recent archaeological simulation, providing a sense of its diversity while remaining attentive to the intellectual lineages which connect models. The paper also suggests which are or have been the dominant areas of application, whether numerically or in terms of their perception. Ultimately, it demonstrates that the pessimism of earlier reviews was not wholly warranted and that computer simulation has now acquired methodological maturity in at least some areas of archaeological enquiry.

M. W. Lake $(\square)$

UCL Institute of Archaeology, 31-34 Gordon Square, London, WC1H 0PY, UK

e-mail: mark.lake@ucl.ac.uk 
It is as well to be clear at the outset that this paper does not attempt to argue the case for computer simulation and nor is it a discussion of simulation method per se. I have discussed the former in a complimentary paper (Lake 2014) which covers both the rationale for archaeological simulation in general, and epistemic and ontological issues relating to agent-based archaeological simulation in particular. Arguments for the utility — or even necessity — of computer simulation in archaeology can also be found in the introduction to the edited collection Dynamics in Human and Primate Societies: Agent-Based Modelling of Social and Spatial Processes (Kohler 2000), Premo et al.'s (2005) paper Making a Case for Agent-based Modeling, Premo's papers Exploratory Agent-based Models: Towards an Experimental Ethnoarchaeology (Premo 2007) and Equifinality and Explanation: The Role of Agent-Based Modeling in Postpositivist Archaeology (Premo 2010), and Costopoulos' entry in the Handbook of Archaeological Theories (Costopoulos 2009). Reviews of simulation method can be found in papers by Cooke (1979), Aldenderfer (1981a) and Lake (2001a). Those seeking a textbook-style introduction to computer simulation could consult Grimm and Railsback's Individual-Based Modeling and Ecology (2005) and Agent-Based and Individual-Based Modeling: A Practical Introduction (Railsback and Grimm 2012), both of which focus on agent-based simulation and have much to offer archaeologists despite being aimed at ecologists. Alternatively, Gilbert and Troitzsch's (1999) Simulation for the Social Scientist introduces and compares a wider range of simulation techniques.

Although the reader is referred to the sources just cited for a detailed account of simulation methodology, a review such as this necessarily makes certain assumptions and uses terminology that requires explanation, so it is worth very briefly reviewing what counts as simulation, how simulation is used and what are the main methods of simulation. It is widely recognised that archaeologists routinely build models (Kohler and van der Leeuw 2007, p. 3), although they may not be explicit that this is what they are doing. As Clarke (1972, p. 2) famously declared 'models are pieces of machinery that relate observations to theoretical ideas' and the subject of this paper is the subset of models that Clarke labelled 'iterative non-iconic analogues' (Clarke 1972, Fig. 1): models which represent some facet of the real world as a set of variables linked by mathematical or logical conditions and which are studied by repeatedly replacing those variables with numbers until some specified conditions are met. In practice, such models are studied by implementing them as a computer program so that the computer can perform the requisite calculations-typically numbering many thousands, even millions. In archaeological writing the term 'computer simulation' is often reserved (e.g. Aldenderfer 1981a, pp. 13-14) for computational models of change through time. The point of this emphasis (see Lake 2001a for a detailed discussion) is to distinguish computational models of the unfolding of a system or process from those which are used to derive a numerical solution to an analytically intractable mathematical model which is not explicitly concerned with the passage of time. The latter would include, for example, various kinds of optimality model, for instance of subsistence behaviour (e.g. Belovsky 1987), in which only the end state - in this case the optimal subsistence strategy - is of interest, but not how it was arrived at. A further narrowing of scope for the term 'computer simulation' was proposed by Doran and Hodson (1975, p. 286), who suggested that simulation models one process by another which 'is itself an abstracted representation 
of the target real-word process'; in other words, not only is computer simulation of change through time, but change occurs by a process that is in some way analogous to the process of change in the real world. The closeness required of that analogy is a matter of debate and what is deemed acceptable typically correlates with both the scale of analysis and the simulation method adopted.

There are two main ways in which commentators have categorised the purposes for which simulation is used in archaeology. One focuses on the intention of the researcher(s) conducting the simulation. Thus, for example, Mithen (1994, pp. 176177) distinguished simulations conducted to test hypotheses, to support theory building and to support the development of methodology (see Lake 2010 for discussion augmented with examples). When simulation models are used to test hypotheses the aim is usually to determine what actually happened in the past by comparing the output of a simulated process against the archaeological evidence. In contrast, the use of simulation models to support theory building - so-called heuristic modelling - does not necessarily, or even usually, involve detailed comparison of output against the archaeological record; in this case the purpose is not to test what happened in the past, but rather to understand how certain processes work and what sort of changes could plausibly have occurred. Methodological, or 'tactical' (Orton 1973), simulations are those conducted to develop and/or test archaeological methods, usually by assessing the ability of those methods to identify meaningful patterns from a known (simulated) reality. These three categories are used throughout this paper as a useful device for teasing apart major trends in the history of archaeological simulation, but it is important to recognise that the distinction between hypothesis-testing and theory-building simulation as conceived by Mithen is not always so clear cut in practice. On the one hand, comparing simulation output with archaeological evidence can ultimately contribute to theory building (e.g. Kohler and Varien 2012), while on the other hand simulation can be used to directly test hypothesis which are more about possible processes (e.g. the effect of parameters on model dynamics) than about what actually happened in the past (see Premo 2010, pp. 29-30).

An alternative classification of simulation models places greater emphasis on who benefits in what manner from the simulation, as witnessed in Aldenderfer's (1981a, p. 20) restatement of Innis' (1972) distinction between 'conceptual', 'developmental' and 'output' utility. Conceptual utility refers to the understanding gained from simply formulating a conceptual model, whereas developmental utility refers to the further benefit that accrues as a result of the discipline imposed by attempting to implement the conceptual model as a simulation model. Conceptual and developmental utility are considered to benefit the researcher(s) actually engaged in the model-building process. By contrast, output utility refers to benefits gained by others not involved in the model-building process, when 'the output of a simulation model is used to explore or explain some other event or process' (Aldenderfer 1981a, pp. 20-21). It should be noted that practitioners of archaeological simulation do not always agree about how it can be used to greatest effect: several relatively recent programmatic statements were cited above, but a more comprehensive list would include: Aldenderfer 2010; Costopoulos 2009; Costopoulos 2010; Kohler 2000; Kohler and van der Leeuw 2007¹ Lake 2010; van der Leeuw and McGlade 1997a; Premo et al. 2005; Premo 2006a; Premo 2008; Premo 2010; Wobst 2010; Wright 2000; Wright 2007.

\footnotetext{
${ }^{1}$ Although Kohler and van der Leeuw are not concerned with simulation specifically but model-based archaeology more generally.
} 
Over the years archaeological simulation models have been implemented using a variety of methods derived from the physical sciences, computer science and the life sciences. Many archaeological simulation models are what one might term methodologically nonparadigmatic, that is, their creators do not explicitly identify them with any particular established method. These models are often technically simple, perhaps requiring the iteration of an equation or other logical expression in a widely used general-purpose numerical programming environment. Other archaeological simulation models are associated with a particular modelling paradigm: in the last 15-25 years this has most often been either dynamical systems modelling or agent-based modelling. Dynamical systems models use mathematical equations to determine the change through time of one or more quantifiable properties of a system and are closely associated with the mathematical approaches to morphogenesis (structural or organisational rather than purely quantitative change) that characterise catastrophe theory (Zeeman 1977) and chaos theory (Schuster 1988). These models take the form of coupled difference equations, which determine how much a variable increases or decreases in a finite amount of time, or alternatively, differential equations, which describe rates of change at a moment in time. Either way, dynamical systems models share three key properties: they must be expressed mathematically, they are ultimately deterministic (which does not, however, mean that they necessarily lack the capacity to surprise - especially in the case of highly non-linear models) and they usually treat the target system as an undifferentiated whole. Agent-based models, at least in their most common form, merge properties of multi-agent systems developed in artifical intelligence (Ferber 1999) with cellular automata popularised by complexity science (Wolfram 1986). Consequently, in these models the focus is very much on the behaviour and often reasoning of goal-directed micro-level agents inhabiting some kind of environment. The environment may simply comprise other agents, perhaps arranged in a network, or it may also include a geographically referenced model of the distribution of various resources required by the agents. Other possible extensions include explicit modelling of agent knowledge, individual agent learning and cultural learning, as well as the response of the environment to agent activity (for example, slower renewal of resources due to over-exploitation). Compared with dynamical systems models, the agent-based modelling paradigm is more flexible in that it does not require formal mathematical expression of the model. In addition, agent-based models can more closely mimic the actual processes that drive change in a system, for example individual people making decisions. However, these properties can make it more difficult or impossible to use well-established mathematical tools to analyse the behaviour of agent-based models, thus necessitating what one might call a more profoundly 'experimental' approach to learning about the target real-world system.

\section{A Survey of Archaeological Simulation}

Given that the purpose of this paper is to update the published history of archaeological computer simulation, the following survey moves fairly swiftly through the 1970s and 1980s before considering the last 20-25 years in more detail. In previous accounts, McGlade (2005) and Lake (2008) broadly agreed that the history of archaeological simulation can be divided into four phases: a pioneer phase (late 1960s-early 1970s); a mature phase characterised by significant diversification of purpose (mid-late 1970s); a period of pessimism and inactivity (1980s); and finally a 
renewal of interest and optimism (late 1980s-early 2000s). This scheme offers a useful point of departure, although in the concluding comments I question the notion of 'maturity' and when that was achieved.

The Pioneer Phase and Subsequent Diversification of Purpose (Late 1960s-Early 1980s)

Anthropologists (Hays 1965) and archaeologists (Doran 1970) were introduced to simulation in the late 1960s and early 1970s, when computers first became available as tools for use outside the fledgling computer sciences. Whallon's (1972, p. 39) survey of the use of computers in archaeology listed two simulation studies and he predicted that 'because of its real suitability to many of the current problems of archaeology and for working in a systemic frame of reference, [simulation] will be one of the burgeoning fields of activity in the next few years'. Indeed, by 1975 most of the archaeological problems that even today make up the core 'territory' of archaeological simulation had been tackled: demography and information exchange (Wobst 1974), hunter-gatherer subsistence strategies (Thomas 1972), the settlement patterns of small-scale societies (Cordell 1972; Zubrow 1971), and colonisation (Levison et al. 1973). The only major problems not represented among the earliest archaeological computer simulations were the functioning of exchange systems and the growth and decline of civilisations, but even these were the subject of simulation by the end of the decade. The early models were very much of their time in two ways. First, they did, as Whallon predicted, adopt the systemic perspective favoured by the New Archaeology (especially as espoused by Clarke 1968, 1972) to construct algorithmic or mathematical models of processes involving the flow of information, energy, or materials through whole societies, sometimes in response to environmental change and often incorporating simple feedback representing, for example, the effect of population growth. Second, as McGlade (2005, pp. 563-564) has discussed at length, the pioneering simulation models reflect the rather dogmatic positivism of the early New Archaeology in that they sought to test hypotheses by predicting what ought to have happened in the real world.

The period from the mid 1970s to early 1980s has been described as a 'mature phase' of simulation modelling (McGlade 2005, p. 564), one which saw the publication of three important edited volumes: Simulation Studies in Archaeology (Hodder 1978), Transformations: Mathematical Approaches to Culture Change (Renfrew and Cooke 1979) and Simulations in Archaeology (Sabloff 1981). These collections and other works bear witness to greater diversity in both the subject matter and purpose of simulation. Settlement pattern (Zimmerman 1977; O'Shea 1978; Chadwick 1979; Gunn 1979; Hodder 1979) remained a popular subject and there was continued interest in demography (Black 1978) and hunter-gatherer subsistence (Mosimann and Martin 1975), but simulation was also used to study trade and exchange (Hodder and Orton 1976; Wright and Zeder 1977; Elliott et al. 1978) and even the rise and fall of entire civilisations (Hosler et al. 1977; Cooke and Renfrew 1979; Zubrow 1981). Greater diversity in the purpose of these models can be attributed to the waning optimism of the New Archaeology as it became clear that it is seldom, if ever, possible to directly reconstruct the functioning of societal systems from the archaeological evidence without developing an elaborate body of middle range theory to first infer the specific (dynamic) behaviours that created the (static) archaeological record (Binford 1977). Thus explicitly 
hypothesis-testing simulations (e.g. Elliott et al. 1978; O'Shea 1978; Chadwick 1979; Gunn 1979) tended to be narrower in scope than had previously been the case, focusing in on only part of a larger problem rather than attempting to predict the content of the archaeological record by simulating an entire system of behaviour. Conversely, the more ambitious 'whole society' (Aldenderfer 1998) simulations (e.g. Hosler et al. 1977; Cooke and Renfrew 1979; Zubrow 1981) were more used for heuristic purposes, to generate rather than test hypotheses. Indeed, Renfrew (1979b, p. 202) made it quite clear that in his view 'simulation is not explanation', but rather a means of exploring the implications of a model. In addition to these hypothesis-testing and heuristic models, the period from the mid 1970 s to the early 1980 s also saw the development of tactical simulations designed to develop archaeological methods. These included models designed to test the ability of statistical methods to tease apart the causes of artifact discard (Aldenderfer 1981b) and dispersal (Hodder and Orton 1976), the impact of edge-effects on nearest neighbour analysis (Donnelly 1978) and the efficacy of sampling methods (Ammerman et al. 1978).

\section{Hiatus (the 1980s)}

Doran and Hodson were not impressed with the first tranche of archaeological simulation models, despite their early support. In 1975 they argued that: 'The established value of computer simulation techniques in other fields, together with the complexity of many archaeological problems, suggests that such techniques have archaeological potential. But it must be admitted that there is virtually no direct evidence in support of the suggestion' (Doran and Hodson 1975, p. 203). In their view, existing models were either so simplistic that they barely warranted the use of simulation, or else they required more input data than was available. To some extent their criticism was answered by the narrowing of remit and/or adoption of a more hueristic approach to modelling that characterised the diversification of archaeological simulation. Nevertheless, by 1981 Aldenderfer conceded that '.... a majority of archaeologists consider simulation mildly interesting but on the whole not particularly useful in the conduct of archaeological research' (Aldenderfer 1981a, p. 12). There was not, however, a complete cessation of archaeological simulation in the 1980s. Tactical modelling continued with Orton's (1982) experiments to assess the performance of measures of quantity of pottery, Yiannouli and Mithen's (1986) test of space syntax analysis, and van der Velde's (1987) model of postdepositional decay. There were also some models of past processes, but these all tackled very specific aspects of past behaviour rather than the functioning or evolution of societies as a whole. Thus Mithen (1988b) simulated red deer and reindeer yields under different intensities of hunting, Reynolds $(1986,1987)$ modelled huntergatherer resource scheduling and Potts (1988) modelled hominin stone-caching. Overall, however, fewer than ten simulation projects were published after 1982 and the remainder of the decade is universally characterised as one of considerable pessimism about the utility of simulation.

Several reasons have been suggested for the failure of simulation to become part of mainstream archaeological practice and/or its relative decline in the 1980s. In comments made at the 2005 Annual Conference of the Society for American Archaeology, Wobst concluded that the 'actual explanation for why simulation has not caught on in the discipline' is 'the very complexity and numerateness of most 
simulation method' (Wobst 2010, p. 10). According to his account, there are few archaeologists with the skills to build a simulation model that addresses a genuinely interesting possible explanation and even fewer with the expertise to critically assess their own models and those of others. This is true, but Wobst's comments on the limitations of the method itself are also interesting, particularly with regard to its optimal niche and its ability to deal with morphogenesis. He argued that simulation is most useful when dealing with between 3 and 10-11 variables because a problem involving just one or two variables is more productively tackled using mathematical methods, while if there are too many variables it becomes impossible to devise a robust experimental design. Wobst suggests that this optimal range for simulation satisfies neither 'paradigmatically committed mainstream archaeologists', who seek explanation in terms of one or two driving forces rather than 'the simultaneous and well-integrated contribution of many variables', nor 'really committed holistic practitioners', 'who wish to incorporate as many variables as possible' (Wobst 2010, p. 10). He also argued that 'simulation cannot deal very well with structural change, with rule change in midstream' (Wobst 2010) as such change can only be achieved by creating meta-rules to specify the conditions under which rule change occurs. Wright (2000, p.376) made a similar point in another conference review, suggesting that the early attempts to model network formation (Wobst 1974) and foraging behaviour (Thomas 1972) were not pursued in part because of the inability of these early models to deal with emergent phenomena'.

The deficiencies in simulation method identified by Wobst and Wright are not absolute, but relative to requirements determined by the purpose of the modelling exercise and the theoretical context in which it is conducted. The earliest simulations were unable to generate systemic change or emergent phenomena, but the early New Archaeology provided a favourable theoretical climate in which the deterministic account of system functioning provided by these models was not perceived to be problematic. This happy coincidence between what was technically possible and theoretically acceptable was ruptured in the very late 1970s and early 1980s. Colin Renfrew and Ian Hodder were both major contributors to the simulation literature and their different theoretical trajectories largely encapsulate the two principal forces that undermined the use of simulation in the 1980s.

In the introduction to his 1978 edited volume Simulation Studies in Archaeology, Hodder expressed optimism about the utility of simulation in archaeology (Hodder 1978, p. viii), yet just four years later, in one of the founding works of postprocessual archaeology, he rejected the positivist inferential strategy and functionalism of the New Archaeology in favour of the hermeneutic interpretation of contextual meanings (Hodder 1982). Ironically, the results of Hodder's own simulations (Hodder and Orton 1976) were a contributory factor in his volte-face because they revealed how the problem of equifinality could profoundly undermine attempts to quantitatively test hypotheses about settlement pattern and trade mechanisms. There was no place for computer simulation in postprocessual archaeology because its primary use for testing or generating hypotheses simply did not fit into the new inferential framework, which in its most extreme formulation rejected scientific method outright (see papers in Edmonds et al. 1990). Furthermore, accessible early 1980s simulation technologies offered relatively little to support the modelling of individual actors and their thought processes, and even when this was later attempted (e.g. Mithen 
1990) postprocessual archaeologists argued that such models enforced a very particular and, in their view, inappropriate concept of rationality (see Thomas 1991 and commentary in Lake 2004).

In the late 1970s and early 1980s, Colin Renfrew had also edited volumes collectively espousing the value of mathematical modelling and in some cases computer simulation, specifically Transformations: Mathematical Approaches to Culture Change (1979) and Explanation in Archaeology (1982). Unlike Hodder, Renfrew did not explicitly turn his back on simulation and he continued to defend scientific inference, but in retrospect it can be argued that the direction he was pursuing undermined the short-term prospects for simulation, albeit unintentionally. Together, Transformations and Theory and Explanation in Archaeology laid out an ambitious agenda that focused on the heuristic value of modelling for generating hypotheses about the functioning and morphogenesis of entire societal systems (McGlade 2005, pp. 567-70). This, of course, emphatically aligned simulation with a systemic approach to past societies which was about to become deeply unfashionable among those persuaded by the postprocessual critque (Shanks and Tilley 1987) of processual archaeology. More subtly, it is also likely that that Renfrew's introduction of concepts from the developing science of non-linear systems-concepts such as emergent phenomena and self-organization - not only lead to a level of abstraction that effectively rendered simulation irrelevant to many more practically minded archaeologists, but was also ahead of its time in terms of the preparedness of archaeologists to grapple with the new concepts, as well as the lack of accessible software to implement appropriate simulations. Furthermore, Renfrew increasingly applied himself to the task of defending scientific archaeology against the postprocessual critique. His solution was an 'archaeology of mind' (Renfrew 1982), later developed into a programme for cognitive archaeology (Renfrew 1994), which would put decision-making and ideology back into the otherwise rather behaviourist systems approach. However, as already noted in the context of Hodder's new focus on meaning, 1980s simulation technologies offered relatively little to support the modelling of cognition (but see Reynolds' 1987 model of huntergatherer resource scheduling adaptations for evidence of a lag in archaeological awareness of developments in computer science).

\section{Renaissance (the 1990s)}

Previous commentary on the history of archaeological simulation is unanimous that the 1990s saw a resurgence of archaeological simulation (Aldenderfer 1998; Costopoulos and Lake 2010; Lake 2001a, 2008; McGlade 2005; Wright 2007). However, as already noted, archaeological simulation did not entirely die out during the 1980s, so it is worth considering the exact nature of this resurgence. In fact, I estimate that approximately ten archaeological simulation studies were undertaken in the 1980s and thirteen in the 1990s. Clearly neither is a large number in absolute terms, but nor is the increase anything approximating an order of magnitude. Among the commentaries published to date only Wobst seems to recognise this reality: he commented at the Annual Conference of the Society for American Archaeology in 2005 that 'Ever since the early eighties, simulation has been virtually dead in archaeology, present company excepted' (Wobst 2010, p. 9). The reason why my estimates appear to tell a different story from the 
usual account is that they attempt to control for cases where substantial development of the model occurred in the decade prior to publication and they discount multiple publications of what is essentially the same model. What we learn from them is that the resurgence of simulation in the 1990s was more a matter of perception that of the actual numbers of models being built.

There are two main reasons why the use of simulation is perceived to have increased in the 1990s. The first and most trivial is an accident of history: several important studies that were initiated and largely completed in the late 1980s were not published until the 1990s, notably Mithen's (1990) Thoughtful Foragers and several models in van der Leeuw and McGlade's (1997a, b, c) Time, Process and Structured Transformation in Archaeology. Indeed, the fact that the latter appeared only three years before Kohler and Gumerman's (2000) influential collection of agent-based models, Dynamics in Human and Primate Societies, provided a real sense of end-ofmillennium momentum even though the underlying research had actually taken place over the best part of a decade.

The more profound reason why it is perceived that there was a resurgence of simulation in the 1990s relates to a contrast between the 1980s and 1990s in terms of the nature of the studies published, how they articulated with archaeological theory and how this was presented. It has already been noted that simulations developed and published in the 1980s were typically either tactical, or they focused on tightly bounded problems. Tactical simulation continued in the 1990s (Yorston et al. 1990; Lockyear 1991), so the real contrast with the 1980 s is to be found in simulations about the past. In a 1998 review of quantitative methods in archaeology, Aldenderfer suggested that 1980s simulation models largely functioned as an 'adjunct to middle range and formation process theory' (Aldenderfer 1998, p. 104) whereas the 1990s saw 'the return of whole society modelling' (Aldenderfer 1998, p. 103). Although there is unquestionably some truth in this characterisation of the change, what is even more universally true is that models published in the 1980s were presented differently from those published in 1990s (or developed in that decade but published early in the new millennium). The 1980s simulations of past processes were largely presented as part of an argument about past behaviour rather than being about simulation: Mithen's (1988b) model of hunting returns was presented in a paper about the ecological context of palaeolithic art, published in the anthropological journal Man; Reynolds' (1986, 1987) work on hunter-gatherer resource scheduling appeared as a chapter in Flannery's classic report on archaeological investigations at Guilá Naquitz; and Potts' (1988) simulation of stone-caching appeared as part of his monograph on early hominin activities at Olduvai. It is true that both Mithen (1986) and Reynolds (1987) wrote about technical aspects of their simulations, but these appeared in outlets peripheral to mainstream archaeology: Science in Archaeology and the European Journal of Operational Research respectively. By contrast, simulation models published in the 1990s and very early 2000s were much more likely to be presented as part of a programmatic statement about the value of simulation and, in particular, its relationship with archaeological theory. For example, the simulations presented in Mithen's 1990 Thoughtful Foragers (not cited by Aldenderfer) cannot be characterised as 'whole society modelling', but are undoubtedly offered in part as a contribution to wider theoretical debate. Indeed, this is the earliest of three books which collectively illustrate renewed optimism about the utility of simulation, but which also illustrate different strands in a new convergence of simulation technology and archaeological theory. 
In essence, Mithen's Thoughtful Foragers offers a book-length manifesto for a cognitive prehistoric archaeology grounded in behavioural ecology and realised with the aid of simulation. Thoughtful Foragers is not about simulation any more or less than it is about archaeological method and theory, or about certain substantive problems in European Palaeolithic and Mesolithic archaeology, but it certainly is an optimistic declaration - and practical demonstration - of the importance of simulation in the project of building an archaeology of mind as a scientific counterweight to postprocessual archaeology. Behavioural ecology (specifically optimal foraging theory) provided Mithen with a route to modelling past cognition (Mithen 1989) and as we shall see, evolutionary archaeology, in its various guises (Lake 1997; Shennan 2008), has been a significant sponsor of simulation ever since. Mithen's simulation of hunter-gather decision making is an example of an agent-based model, even though it predates the availability of generic agent-based modelling software 'platforms' and differs from most contemporary agent-based models by not explicitly modelling space. These differences partly reflect the fact that Mithen arrived at agent-based modelling not via the new science of complexity, but via a commitment to methodological individualism (Lake 2004, p. 194) as a strategy for inferring past individual decision-making from the aggregate properties of the archaeological record (Mithen 1988a). This blend of behavioural ecology and methodological individualism also informed Lake and Mithen's (Lake 2000a, 2000b) later model of Mesolithic land-use (MAGICAL), which incorporated geographically referenced space and more sophisticated group decision-making. MAGICAL was developed as an extension to the open-source GRASS geographical information systems software, but from a technical perspective it has many of the trappings of contemporary agent-based modelling platforms, including a scheduler and (partially) end-user configurable production rules. Indeed, inclusion of the MAGICAL model in Kohler and Gumerman's (2000) Dynamics in Human and Primate Societies probably owes as much to its technical attributes, particularly the close coupling with geographical information systems, as its theoretical stance.

Kohler and Gumerman's (2000) edited volume Dynamics in Human and Primate Societies marks the coming-of-age of agent-based modelling in archaeology (McGlade 2005, p. 581, Wright 2007). Kohler's introductory chapter (Kohler 2000) is, like Thoughtful Foragers a decade before, unashamedly pro scientific inference and programmatic, and it is similarly optimistic about the prospects-even necessity — of archaeological simulation. There are other important points of overlap too: both Kohler and Mithen agree with Collingwood that 'historical processes involve the actions of self-aware individuals' (Kohler 2000, p. 3), but reject the notion that this mandates a complete separation of culture and biology; and both agree that the archaeological record largely comprises a palimpsest of these actions. Nevertheless, Kohler's agenda is subtly different in that he is more interested in simulating the evolution of societal systems as part of a 'generative social science' (Kohler 2000, p. 9). For example, while Mithen draws social inferences from the fact that his simulations suggest that two different Mesolithic groups had different hunting goals, he does not attempt to simulate the long-term evolution of these goals ${ }^{2}$ or their social consequences. In contrast, several of the simulations presented in Dynamics in

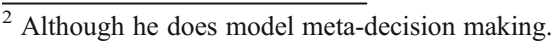


Human and Primate Societies model the evolution of social phenomena such as cooperation (Lansing 2000; Pepper and Smuts 2000), dominance hierarchies (te Boekhorst and Hemelrijk 2000) and even systems of shared meaning (Skyrms 2000). These models are closely aligned with the sociological programme of growing artificial societies from the bottom-up (Epstein and Axtell 1996; also Gilbert and Conte 1995), which was in turn inspired by the strand of complexity theory (Waldrop 1992) which deals with complex adaptive systems (Holland 1995) and, in particular, emergent phenomena (Holland 1998; Gilbert 1995 for relevance to social systems). However, it can be argued that the more specifically archaeological (in terms of both problem formulation and empirical grounding) models in Dynamics in Human and Primate Societies only partly implement Kohler's vision for generative social science. Neither Kohler et al.'s (2000) model of ancestral Puebloan settlement determinants in southwestern Colorado nor Dean et al.'s (2000) model of Anasazi settlement pattern in Arizona allow the rules governing settlement to evolve during the simulation ${ }^{3}$. Conversely, both models are used to simulate settlement over timescales that are long enough to warrant the implementation of externally forced environmental change and Kohler et al.'s model goes even further by explicitly incorporating negative feedback between the duration of farming and crop productivity. Kohler was himself careful 'not [to] confuse the promise of these approaches with what they have accomplished to date' (Kohler 2000, p. 13), but taken overall, there is no doubt that Dynamics in Human and Primate Societies provided an influential statement of the potential for agent-based simulation as a means of modelling long-term social change without losing sight of the individual and household actions that underly it. As a selfproclaimed manifesto for 'putting social sciences together again' (Kohler 2000, p. 14) it certainly sketched how agent-based modelling might help reconcile processual interest in societal systems with postprocessual concern for human agency (but see the cautionary perspectives offered by O'Sullivan and Haklay 2000 and Beekman 2005a) and, perhaps to a lesser extent, how it might help overcome the tendency to overlook the feedback between human decision making and the environment in which decisions are made.

The third book-length treatment of archaeological simulation published in the 1990s was van der Leeuw and McGlade's (1997c) edited volume Time, Process and Structured Transformation in Archaeology. The editors' introduction is no less programmatic than Kohler's introduction to Dynamics in Human and Primate Societies and is similarly concerned with the long-term societal change, but their argument that 'dynamical systems approaches have a great deal to contribute to our understanding of societal structuring' (van der Leeuw and McGlade 1997a, p. 19) reflects an older intellectual lineage. Whereas Kohler draws explicitly on the notion of complex adaptive systems that came to the fore in the first half of the 1990s, van der Leeuw and McGlade take their cue from mathematical approaches to morphogenesis which have their foundation in studies of nonlinear dynamics in the late 1970s (see McGlade 2005, pp. 574-575 for more detail) and which were introduced to archaeologists at some length in Renfrew and Cooke's (1979) Transformations: Mathematical Approaches to Culture Change. This difference is less surprising when one considers that the papers gathered together in Time, Process and Structured

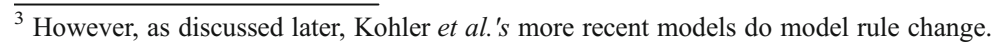


Transformation in Archaeology were first presented at a conference in 1990. Indeed, there is considerable continuity between the editors' theoretical stance and the project proposed by Renfrew in the late 1970s in Trajectory Discontinuity and Morphogenesis: The Implications of Catastrophe Theory for Archaeology (Renfrew 1978) and System Collapse as Social Transformation (Renfrew 1979a). If van der Leeuw and McGlade offer a realignment of simulation with the post-Symbols in Action (Hodder 1982) landscape of archaeological theory, it is not by rejecting systems thinking and wholeheartedly embracing the individual agency to which agent-based modelling so readily lends itself; rather, they seek to distance the science of non-linear systems from "the worst excesses of positivist "explanation" while cautioning that excessive focus on 'knowledgeable agents' risks obscuring alternative levels of description at which there are interesting structural similarities in human social organisation (van der Leeuw and McGlade 1997a, p. 7). However, as McGlade (2005, p. 575) later observed, Time, Process and Structured Transformation in Archaeology actually presents a fairly eclectic mix of simulations including non-linear dynamical systems models (McGlade 1997a; van der Leeuw and McGlade 1997b), but also a Leslie Matrix model of the impact of human predation on mammoth populations (Mithen 1997) and a GIS-based epidemiological model of the spread of disease in the New World during the Sixteenth Century (Zubrow 1997). As with Dynamics in Human and Primate Societies, the most archaeologically grounded simulations in Time, Process and Structured Transformation in Archaeology are arguably also those that travel least far down the road mapped out in the editorial.

Taken together, Thoughtful Foragers, Time, Process and Structured Transformation in Archaeology and Dynamics in Human and Primate Societies demonstrate renewed optimism about the value of simulation. Crucially, each, in a different way, sought to demonstrate that simulation has a valuable role to play in archaeological explanation despite the widespread rejection of the largely deterministic and behaviourist form of systemic thinking that had characterised the New Archaeology of the 1970s. With the benefit of hindsight it can now be seen that Time, Process and Structured Transformation in Archaeology was the least successful of these initiatives when measured by the number of subsequent models which implemented the editors' vision. Even so, the long gestation time of this volume resulted in it adding greatly to the sense of momentum at the end of the 1990s. Furthermore, fixation on the programmes laid out in the introductions to these two edited volumes runs the risk of overlooking other themes represented in their pages and elsewhere.

Two themes stand out as worthy of explicit note because they point to additional sources of inspiration for archaeological simulation and/or presage developments in the new millennium. Artificial intelligence (AI) is a good example of the former and very explicitly found its way into archaeological simulations with Reynolds and Zeigler's (1979) invocation of aspects of Minsky and Papert's (1969) foundational work on artifical neural networks to study the role of resource scheduling as a driver for the adoption of agriculture. Reynolds' (1986; 1987) later model of hunter-gatherer resource scheduling at Guilá Naquitz is probably better known to most archaeologists; in this model he employed the widely used AI formalism of a production system to model incipient farmers altering their plant resource acquisition strategies. Biskowski's 1992 proposal for the use of expert systems within archaeological simulation is in a similar vein and, although it seems never to have been implemented, is unusual for having been 
published in an edited volume that was about archaeological computing more generally. Reynolds' contribution to Time, Process and Structured Transformation in Archaeology drew on the AI concept of an autonomous learning system to propose a model of the interaction of biological and cultural evolution (Reynolds 1997). There is some convergence between Reynolds' work and that of Mithen and Lake - even though the former was strongly grounded in computer science and the latter more 'home grown' within archaeology — notably between strategy-change in Reynolds' Guilá Naquitz model and 'meta decision-making' in Mithen's Thoughtful Foragers (Mithen 1990), and between Reynolds' model of the interaction of biological and cultural evolution and Lake's (1996) model of the biological evolution of cultural learning. Like Reynolds, Doran contributed to both Time, Process and Structured Transformation in Archaeology and Dynamics in Human and Primate Societies, but whereas Reynolds' work has its roots in late 1960s and 1970s AI research on information processing, Doran's contributions draw on 1980s AI research on distributed AI and multiple agent systems. The latter emphasises information processing among collections of entities (agents), but also extends to consideration of the environment inhabited by those agents and the emergent properties of systems of agents. As Doran pointed out in his 1997 commentary Distributed AI and Social Complexity, distributed AI cuts across established theoretical categories (Doran 1997, pp. 285-286), mixing concern with individual agent cognition with interest in the properties of non-linear systems. His own attempt to create an agent-based simulation of Mellars' model for the emergence of increased social complexity at the Middle-Upper Palaeolithic transition in south-western France (Doran et al. 1994; Doran and Palmer 1995; Doran 1997) testifies to this mixed heritage: by implementing agents who interact within a simulated environment, reason and form groups, Doran blends more traditional AI concern with, for example, production rules, with interest in long-term societal change (see also Doran 1982, 1989).

A second theme which to some extent cross-cuts Time, Process and Structured Transformation in Archaeology and Dynamics in Human and Primate Societies, and which is represented elsewhere is growing concern with explicit treatment of space. Agent-based modelling lends itself particularly well to the construction of spatial models so it is no surprise that many contributions to Dynamics in Human and Primate Societies include a spatial component. This ranges from an abstract 'grid' or raster representation of a synthetic 'landscape' (te Boekhorst and Hemelrijk 2000; Pepper and Smuts 2000), through a similar representation of real geographical space (Dean et al. 2000; Kohler et al. 2000 and also Kohler and Carr 1997; Lansing 2000 and Lansing and Kremer 1993) to direct integration with a GIS (Lake 2000a and also Lake 2000b). Thus by the turn of the millennium archaeological simulation already included examples of both of what came to be known as 'loose-coupled' and 'closecoupled' spatial agent-based modelling (Westervelt 2002). Spatial modelling was not, however, limited to agent-based models. Two simulations using rather different theoretical and methodological apparatus and conducted on rather larger spatial canvasses presage a major growth area for archaeological simulation in the next decade. Young and Bettinger (1995) and Steele et al. (1996, 1998) both used FisherSkellam type reaction-diffusion equations to model population growth and dispersal across grids representing the Old World and North America, respectively. Of course, a grid or raster map is not the only possible form of spatial representation and this is reflected, albeit rarely, in Steele's (1994) use of lattice adjacency (a means of representing connections between entities at grid cells that are not immediately 
adjacent in Euclidean space) to model connectivity in Lower Palaeolithic social networks and perhaps more conspicuously in Zubrow's (1997) aforementioned network model of the spread of disease in the New World.

\section{Expansion (2001 Onwards)}

It was suggested above that the 1990s resurgence of archaeological simulation was more a matter of perception than of any real increase in the absolute number of studies. Indeed Wobst's 2005 comment (at that year's Annual Conference of the Society for American Archaeology) about simulation having been 'virtually dead' since the early 1980s except among a very small group of practitioners (Wobst 2010) is borne out by its treatment in the various textbooks on archaeological computing that appeared between 2000 and 2005. Computer simulation occupies just four pages in Lock's (2003) Using Computers in Archaeology: Towards Virtual Pasts and none at all in McPherron and Dibble's (2001) Using Computers in Archaeology: A Practical Guide. Similarly, simulation fares little better in review articles on archaeological computing: three sentences in Richards' (1998) Recent Trends in Computer Applications in Archaeology and one paragraph in Eiteljorg's (2004) overview Computing for Archaeologists. Indeed, Eiteljorg claims that 'Those interested in simulation today are more likely to use GIS, CAD, or statistics and to compare various predefined scenarios to test possible explanations of development, than to use simulation algorithms or AI algorithms, which have seen little use in archaeology'. The fact that simulation was virtually omitted from textbooks on archaeological computing, but continued to be included in disciplinary handbooks and encyclopedias (Lake 2001a in the Handbook of Archaeological Sciences; McGlade 2005 in the Handbook of Archaeological Methods; Lake 2008 in the Encyclopedia of Archaeology; Costopoulos 2009 in the Handbook of Archaeological Theories) is consistent with it being seen from outside as more as a matter for theoretical debate than a method for routine application.

With the benefit of hindsight, however, it can now been seen that Wobst (2010) and Lake's (2010) pessimism in $2005^{4}$ about the future of simulation was premature. Indeed a real increase in the use of simulation was underway even as they were writing their commentaries. Recall my estimate that approximately thirteen archaeological simulations were developed in the 1990s. By contrast, I estimate that approximately 54 simulations were developed between 2001 and 2010 inclusive and further 16 have been published since 2011 , omitting purely conceptual models and multiple publication of the same model. These figures should be treated with caution because different models involve different amounts of effort and one can argue about which are really archaeological, but nevertheless the difference is surely enough to indicate a substantial change in the fortunes of archaeological simulation. One could attempt to group the c. 70 simulations developed since 2001 along several dimensions, primarily method, purpose, subject matter and utility. A preliminary investigation suggests that there are probably no groups in which membership is invariant across dimensions. Consequently, since the focus of this review has been the relationship between simulation, theory and 'mainstream' archaeology, the following discussion is based around constellations of activity which are probably perceived as relatively homogeneous from outside the simulation community even though that may not be

\footnotetext{
${ }^{4}$ The year these papers were first presented
} 
true in a more technical sense. These groups are: reaction-diffusion models, models of long-term societal change and/or human-environment interaction, models of aspects of human evolution, models of cultural evolution, and finally other miscellaneous models (which may individually be of great worth, but do not fit in to one of the other groups). This scheme is not necessarily the only or 'best' grouping, but it is good enough to reveal some of the key drivers and fault lines in contemporary archaeological simulation.

The use of reaction-diffusion equations to model the growth and dispersal of prehistoric populations dates back to Ammerman and Cavalli-Sforza's (1979) wellknown 'Wave of Advance Model for the Spread of Agriculture in Europe'. As already noted, in the 1990s several researchers extended this approach to model population growth and dispersal across lattices (Young and Bettinger 1995; Steele et al. 1996, 1998). Since 2000 this approach ${ }^{5}$ has been applied to the Neolithic spread of agriculture in Europe in at least nine studies (Pinhasi et al. 2005; Davison et al. 2006; Ackland et al. 2007; Fort et al. 2008; Davison et al. 2009; Patterson et al. 2010; Pérez-Losada and Fort 2011; Fort 2012; Fort et al. 2012). Other applications include the late glacial recolonisation of northern Europe (Fort et al. 2004), the colonisation of the western Pacific (Fort 2003), the diffusion of Clovis projectiles in late glacial North America (Hamilton and Buchanan 2007), and the rather more recent spread of European American settlers (Campos et al. 2006; Fort and Pujol 2007). Many of these studies are discussed in detail in Steele's excellent (2009) review of FisherSkellam type reaction-diffusion models of human dispersals. Two observations are particularly relevant here. The first is to note that Ammerman and Cavalli-Sforza's foundational study was published in Renfrew and Cooke's (1979) Transformations: Mathematical Approaches to Culture Change, so in a sense the intellectual lineage of the reaction-diffusion approach to modelling prehistoric dispersal can be traced back to that systemic approach to culture-change. It is interesting that whereas that approach led to a degree of theoretical soul-searching in the context of aspatial models of long-term societal change (see e.g. Van der Leeuw and McGlade's introduction to Time, Process and Structured Transformation in Archaeology) this does not seem to be equally true of the use of deterministic differential equations to model spatial phenomena. That said, the second observation worthy of comment is that there is a trend towards greater environmental realism in reaction-diffusion models, through the explicit inclusion of environmental heterogeneity (e.g. Davison et al. 2006; Ackland et al. 2007), human impact on the environment (Fedotov et al. 2008) and, most recently, acknowledgement that populations are not necessarily homogeneous with respect to the strategies open to individuals (see Steele 2009, p. 134). Thus in a very general sense reaction-diffusion modelling can be seen as an arena in which there is some convergence between two different intellectual lineages: dynamical systems and agent-based modelling.

In 1998 Aldenderfer predicted 'the return of whole-society modelling' (Aldenderfer 1998, p. 103) and, as discussed above, both Time, Process and Structured Transformation in Archaeology and Dynamics in Human and Primate Societies can be read as manifestos for renewed simulation of long-term societal

\footnotetext{
${ }^{5}$ Some of the following studies use user non-lattice representations of two dimensional space, for example 'rings'.
} 
change, in the first case by means of dynamical systems modelling and the second by means of agent-based simulation. Given the optimism of those books it is curious that fifteen years later models of long-term societal change constitute less than perhaps $20 \%$ of all substantive (i.e. excluding tactical) archaeological ${ }^{6}$ simulations developed since 2000. Very few dynamical systems models have appeared since 1997 and none of a complexity comparable to the exemplars provided by van der Leeuw and McGlade (van der Leeuw and McGlade 1997b; McGlade 1997b). Those that have been published are either 'stylized models' (Janssen and Anderies 2007), 'retain a metaphoric feel' (Beekman 2005b, p. 96), or represent very tightly bounded systems such as the rope pull mechanisms used in the Hallstatt Bronze Ages mines (Heinzl et al. 2012). It seems that researchers attracted to the dynamical systems perspective on morphogenesis have shifted their focus to 'human ecodynamics' (McGlade 1995) or 'socio-natural studies' (van der Leeuw and Redman 2002): that is, the study of the complex interactions between societal and environmental change that play out over long timescales (Dearing et al. 2010). Such studies as have been published to date (e.g. Berger et al. 2007; Kirch et al. 2007) are characterised by a substantial effort to assemble rich longitudinal datasets, significant use of GIS (Verhagen and McGlade 1997) and various kinds of statistical analysis, all brought together in a multi-scalar, multi-model 'interpretive/interrogative framework' (McGlade 1995, p. 128), but one which has not yet included actual computer simulation of long-term change. It remains to be seen whether the lack of large-scale dynamical systems simulation simply reflects the magnitude of the task, or a more fundamental difficulty with capturing human ecodynamics in a mathematically expressed dynamical system. In contrast, the applicability of agent-based modelling to long-term societal change has been more widely advertised-not least in Scientific American (Kohler et al. 2005) and Proceedings of the National Academy of Sciences of the United States of America (Axtell et al. 2002) — although the number of such models is small. The most cited 'big' archaeological agent-based model is Kohler et al.'s model of prehispanic Pueblo settlement pattern in southwestern Colorado. Their 'Village' model has been developed over a period of more than 15 years (see Kohler et al. 2012a for its history) as a major plank in a project whose aim is to understand long-term variability in prehispanic settlement pattern, in particular the extent to which it can be explained by households seeking to maximise their net returns in the face of exogeneous climatic shocks and endogeneous processes of population growth, decline and resource depletion (Kohler et al. 2007, p. 64). The agent-based model (now a suite of models) has developed from a relatively simple model - albeit sophisticated for its time - in which households apply fixed decision-making rules to settlement location (Kohler and Carr 1997; Kohler et al. 2000) to one which uses cultural algorithms to adjust household decision-making among agents who have trading and kin relations (Cockburn et al. 2010) and which includes a realistic but changing environment populated with game (Cowan et al. 2012), wood (Johnson et al. 2005) and springs whose flow is modulated according to a lagged relationship with reconstructed precipitation (Kohler et al. 2007). At present the only other well-developed agentbased model of broadly similar scope and purpose is Wilkinson et al.'s (Christiansen

\footnotetext{
${ }^{6}$ Although some might object that these are among the most archaeological (in the sense of empirically grounded) simulations.
} 
and Altaweel 2006; Wilkinson et al. 2007a, b) model of household production and exchange in the late prehistoric and Bronze Age societies that developed at the onset of urbanization in Mesopotamia. However, in addition, Barton et al. are building a household-level agent-based model of agropastoralism (Barton et al. 2010b) as part of a long-term project on the long-term human 'socioecological dynamics' of Mediterranean landscapes (Barton et al. 1999; McClure et al. 2009); this model will couple with their already well-developed framework for simulating environmental change using GIS (Barton et al. 2010a). These three projects share four characteristics: explicit concern with long-term human-environment interaction couched in terms of human ecodynamics, a high degree of realism, comparison of simulated output with rich archaeological datasets (see Altaweel et al. 2010 for commentary on the kinds of data required for modelling socio-ecological systems using agent-based modelling) and the longevity of the projects themselves.

While the household-scale agent-based models just described may be among the most widely known examples of archaeological simulation, they are certainly not the most numerous. The biggest growth area has been the development of simulations of aspects of human evolution and, perhaps even more so, for theory building and in some cases hypothesis testing in evolutionary archaeology, especially the branch centred on cultural transmission and dual inheritance theory (see Shennan 2008 for a 'map' of contemporary evolutionary archaeology). Although there is some overlap between these two domains, each is considered in turn. Simulation models designed to explore problems in human evolution do not have the kind of ethnographic-scale realism of agent-based models of societal change in later prehistory, either because they model much larger geographical areas, or because they eschew realism in favour of the simplicity that comes with greater abstraction. Two simulation models which exhibit the kind of coarse-grained realism that comes with a continental or even global scale are Mithen and Reed's (2002) and Nikitas and Nikita's (2005) cellular automata models of hominin dispersal from Africa. Both model the Old World as a lattice in which individual cells are differentiated in terms of basic environmental characteristics such as aridity and altitude. It is also the case that both explicitly compare simulation output against features of the archaeological record: Mithen and Reed generate a distribution of possible arrival dates at specific archaeological sites while Nikitas and Nikita attempt to estimate 'the probability of the earliest distribution of hominins throughout Eurasia as suggested by archaeological data' (Nikitas and Nikita 2005, pp. 603-604). All other computer simulations of human evolution published since 2001 are abstract agent-based models intended to assist with hypothesis generation rather than hypothesis testing. Collectively, these models address seven themes: the impact of population structure on the emergence of cultural complexity (Powell et al. 2009, 2010; Premo and Kuhn 2010; Premo 2012a; Vaesen 2012), the role of environmental heterogeneity in promoting enhanced sociality (Lake 2001b; Premo 2005, 2006b; Reynolds et al. 2010), interaction between hominin species/subspecies (Barton et al. 2011; Premo 2012b), the causes of low genetic diversity in Pleistocene hominins (Premo and Hublin 2009; Premo 2012c), the uniqueness of hominin life history (Kachel et al. 2011a, 2011b, 2011c), the impact of cognitive abilities on long-term adaptation in spatially and/or temporally variable environments (Costopoulos 2001; Xue et al. 2011; Wren et al. 2013) and (although this could be considered tactical) our ability to make inferences about hominin 
cognition from the landscape-scale spatial distribution of material in the archaeological record (Brantingham 2003, 2006). In addition to their high level of abstraction, all these models are nevertheless explicitly spatial, focused on one very tightly bounded problem and - with a few exceptions - their presentation in the literature treats the fact that they use simulation as largely unremarkable.

Papers that use simulation for theory building or hypothesis testing in evolutionary archaeology are the least likely to foreground their methodology - they are seldom, if ever, in any real sense about simulation. In part this is because the simulations in question are often very simple in terms of their technical requirements: those that are implemented using agent-based modelling software do not involve complex agent reasoning and behaviour, and others are implemented using widely used numerical computing environments (see Bentley et al. 2007 for a comment on why these methods can be complementary), or even, in at least one case, spreadsheet software (Eerkens et al. 2005). This technical simplicity stems from the fact that these simulations are typically abstract, often but not always aspatial, and have few parameters. That said, it should be noted that theory building often requires rigorous examination of a model's parameter space, which may make experimentation with such models computationally demanding despite their architectural simplicity. As already noted, a major role for simulation within evolutionary archaeology is to explore aspects of cultural transmission and dual inheritance theory. Exploration of the relationship between demography and cultural diversity has largely been conducted in the context of human evolution and a number of simulation studies addressing this theme have already been already been mentioned, although Premo and Scholnick's recent (2011) demonstration that localized unbiased transmission can be confused with biased transmission should be added to that list. Other aspects of cultural transmission tackled using simulation include: the development and testing of 'null models' for cultural evolution by random copying (Hahn and Bentley 2003; Bentley et al. 2004, 2007); comparison of the effect of random copying versus frequency dependent copying on cultural trait distributions (Mesoudi and Lycett 2009); testing hypotheses about the kinds of cultural transmission bias responsible for observed artefact (Bentley and Shennan 2003) and crop (Conolly et al. 2008) diversity; development of a method to directly measure the relative strength of selection as opposed to stochastic processes in cultural evolution (Brantingham 2007; Brantingham and Perreault 2010); exploring the effect of different cultural transmission biases on our ability to reconstruct cultural trait phylogeny (Eerkens et al. 2005); exploring the effect of copying error on cultural trait diversity (Eerkens and Lipo 2005) and the volume of knowledge that can be retained (Andersson 2011); and exploring the effect of cultural transmission on the diversity of adaptive (rather than neutral) traits when payoff is uncertain and/or frequency dependent (Lake and Crema 2012). Apart from cultural transmission, two other evolutionary archaeological topics that have recently been addressed using simulation are the emergence of leadership (Kohler et al. 2012b) and inequality (Bentley et al. 2005; Smith and Choi 2007 ) in small-scale societies and the process of fission and fusion in such societies (Griffin and Stanish 2007; Grove 2011; Crema, this issue).

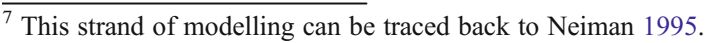


I estimate that models developed to address issues in human evolution and/or evolutionary archaeology account for slightly over $50 \%$ of all archaeological simulation models developed since 2001 and reaction-diffusion models account for perhaps a further $10 \%$, so models addressing other issues make up slightly more than one third of the total. Some of these are the realistic models of long-term societal change which have already been discussed; the remainder are rather diverse in purpose and subject matter, but one aspect they typically share is a foregrounding of methodology — unlike most of the evolutionary models just discussed, the chapters and journal articles in which they appear are often at least partly about simulation.

Two recent simulation models that do not readily fit into the categories already discussed were created for tactical purposes, that is, to assist with the development of archaeological method. Surovell and Brantingham (2007) use a simple numerical simulation to investigate how taphonomic bias can affect frequency distributions of archaeological material in ways that can potentially result in false inferences about past demographic trends. In a similar vein, although using a rather more complex and computationally distributed (parallelised) agent-based simulation, Rubio-Campillo et al. (2011) aim to contribute to the development of battlefield archaeology by simulating a battle and subsequent attrition of material by taphonomic processes and archaeological sampling. Analysis of past military action is also the 'use-case' for another project to develop a distributed agent-based simulation framework capable of handling the 'study [of] behaviour dynamics at a larger scale, involving tens of thousands of agents' (Murgatroyd et al. 2011, p. 489): the 'Medieval Warfare on the Grid' project will eventually be used for a logistical analysis of the Byzantine army's march to the AD 1071 battle of Manzikert in Anatolia (Craenen et al. 2010). Similar work by Rubio-Campillo et al. (2013), focused on European military tactics during the Eighteenth Century War of the Spanish Succession, perhaps takes us even further away from what might reasonably be labelled archaeological simulation. In contrast there can be no doubt about the archaeological applicability of another computationally intensive project which blends simulation and virtual reality: Ch'ng and Stone (2006, Ch'ng 2007) have combined agent-based modelling and gaming engine technology to generate dynamic vegetation models for archaeological reconstruction and interactive visualisation. To date their simulation is capable of synthesising the 'dispersal patterns of natural vegetation communities as they grow, reproduce, and compete for resources' (Ch'ng and Stone 2006, p. 1) and work is underway to add agents representing Mesolithic hunter-gatherers foraging in a landscape now submerged under the North Sea (Ch'ng et al. 2011). Although this is one of-perhaps the - most technologically sophisticated archaeological simulation to date, it is not yet clear what inferential strategy will guide its deployment for the purposes of learning about the past. In contrast the three remaining simulations noted here are all presented in publications which are explicit about their inferential role in a wider archaeological investigation. SHULGI (Branting et al. 2007) was developed to integrate multiple modelling techniques and GIS for the purpose of simulating pedestrian movement; its application to Kerkenes Dağ, a Sixth Century BC. Iron Age site in Turkey is expected to 'determine areas of potential archaeological significance and direct further investigations through field excavations or other archaeological techniques' (Altaweel and Wu 2010, Abstract). Heinzl et al. (2012) present two simulation studies which they use to investigate the mining technology 
used the Bronze Age mining halls at Hallstatt. The first, mentioned earlier, uses a system of differential equations to study alternative rope pull systems, while the second models the use of bronze picks for digging as a rigid body system. In both cases, the aim is to falsify certain propositions and thus 'restrict the total set of possibilities' (Heinzl et al. 2012, p. 32). Finally, Knappet et al. have used numerical simulations of network evolution 'to provide a novel perspective on the possible causes for the demise of Cretan Bronze Age palatial society at c. 1500 BC' (Knappett et al. 2011, p. 1008). As they are careful to point out, their simulation does not prove what happened, but it does allow them to propose the hypothesis that increased trading costs after the eruption of Thera lead to greater centralisation of exchange which in turn decreased the resilience of the exchange network, ultimately sowing the seeds of its demise. In many respects this is one of the relatively few very recent archaeological simulations (but see also Janssen and Anderies 2007) that addresses system morphogenesis using the concepts and language introduced to archaeologists 34 years ago in Transformations: Mathematical Approaches to Culture Change and revived in the introduction to Time, Process and Structured Transformation in Archaeology.

\section{Conclusion}

As noted at the outset of this review, the 'standard' account of the history of simulation has a pioneer phase (late 1960s-early 1970s) followed by a mature phase characterised by significant diversification of purpose (mid-late 1970s) and then a period of pessimism and inactivity (1980s) preceding a renewal of interest and optimism (late 1980s-early 2000s). Given developments since 2001 and the benefit of greater hindsight, this no longer seems the most appropriate characterisation. To start with, one might question in what sense the mid-late 1970s and early 1980s can be viewed as the attainment of 'maturity' when the real explosion in the number of simulations came 20 years later. Furthermore, most of the simulations developed in that period were published in edited collections that were effectively-often explicitly - programmatic statements about the potential of simulation and its proper role in archaeological inference, whereas one might regard publication in books and papers about particular archaeological problems as a more convincing indicator of methodological maturity. Indeed, if one accepts the latter proposition, then what we appear to have is a programmatic phase lasting from the first uses of simulation until the early 1980s and a second programmatic phase from 1990 (the year of publication of Thoughtful Foragers and the Cambridge conference that was later published as Time, Process and Structured Transformation in Archaeology) to 2001 (the year that Dynamics in Human and Primate Societies was published). In this scheme the 1980s, while undoubtedly a period of low activity, is actually one of maturity in the sense that, as documented earlier in this account, most of the simulations published between 1982 and the end of that decade had output utility. The new millennium is similarly characterised by methodological maturity in which a high proportion of publications reporting simulation results do not foreground the method itself, or at the very least balance the account of method with a substantive research conclusion. Of course, the key difference between the 1980s and 2001-2013 is the explosion in the number of 
simulation models, which taken together with their output utility, suggests that simulation really has finally come of age as part of the archaeological toolkit.

The sceptic may point out, however, that simulation has only become unremarkable in certain fields of archaeological enquiry, in particular evolutionary archaeology and the study of human evolution, and cannot therefore yet be considered a 'mainstream' tool in the way that, say, geographical information systems are used in projects concerned with many different periods and conducted in many different theoretical frameworks. This is not the place to debate how one defines 'mainstream', but nevertheless, this observation is not easily dismissed. Does it matter? In one sense the answer must be 'no', not if simulation is now being used productively in areas where it fits naturally into existing inferential frameworks. Conversely, it does suggest that the project of 'putting social sciences together again' (Kohler 2000) remains work in progress and, in particular, that demonstrating the widespread archaeological applicability of what one might call explicitly 'sociological' simulation remains a challenge.

Open Access This article is distributed under the terms of the Creative Commons Attribution License which permits any use, distribution, and reproduction in any medium, provided the original author(s) and the source are credited.

\section{References}

Ackland, G., Signitzer, M., Stratford, K., \& Cohen, M. (2007). Cultural hitchhiking on the wave of advance of beneficial technologies. Proceedings of the National Academy of Sciences, 104(21), 8714-8719.

Aldenderfer, M. S. (1981a). Computer simulation for archaeology: an introductory essay. In J. A. Sabloff (Ed.), Simulations in Archaeology (pp. 67-118). Albuquerque: University of New Mexico.

Aldenderfer, M. S. (1981b). Creating assemblages by computer simulation: the development and uses of ABSIM. In J. A. Sabloff (Ed.), Simulations in Archaeology (pp. 11-49). Albuquerque: University of New Mexico.

Aldenderfer, M. S. (1991). The analytical engine: Computer simulation and archaeological research. In M. Schiffer (Ed.), Archaeological Method and Theory, Vol. 3 (pp. 195-247). Tucson: University of Arizona Press.

Aldenderfer, M. S. (1998). Quantitative methods in archaeology: A review of recent trends and developments. Journal of Archaeological Research, 6, 91-1220.

Aldenderfer, M. S. (2010). Seeing and knowing: On the convergence of archaeological simulation and visualization. In A. Costopoulos \& M. Lake (Eds.), Simulating Change: Archaeology into the TwentyFirst Century (pp. 35-68). Salt Lake City: University of Utah Press.

Altaweel, M., \& Wu, Y. (2010). Route selection and pedestrian traffic: Applying an integrated modeling approach to understanding movement. Structure and Dynamics, 4(2):article 2.

Altaweel, M., Alessa, L., Kliskey, A., \& Bone, C. (2010). A framework to structure agent-based modeling data for social-ecological systems. Structure and Dynamics, 4(1):article 2.

Ammerman, A. J., \& Cavalli-Sforza, L. L. (1979). The wave of advance model for the spread of agriculture in Europe. In C. Renfrew \& K. L. Cooke (Eds.), Transformations: Mathematical Approaches to Culture Change (pp. 275-294). New York: Academic Press.

Ammerman, A., Gifford, D., \& Voorrips, A. (1978). Towards an evaluation of sampling strategies: Simulated excavations of a Kenyan Pastoralist site. In I. Hodder (Ed.), Simulation Studies in Archaeology (pp. 123-132). Cambridge: Cambridge University Press.

Andersson, C. (2011). Paleolithic punctuations and equilibria: Did retention rather than invention limit technological evolution? PaleoAnthropology, 2011, 243-259.

Axtell, R. L., Epstein, J. M., Dean, J. S., Gumerman, G. J., Swedlund, A. C., Harburger, J., et al. (2002). Population growth and collapse in a multiagent model of the Kayenta Anasazi in Long House Valley. Proceedings of the National Academy of Sciences of the United States of America, 99(Suppl 3), 7275-7279. 
Barton, C. M., Bernabeu, J., Aura, E., \& Garcia, O. (1999). Land-use dynamics and socioeconomic change: An example from the Polop Alto Valley. American Antiquity, 64, 609-634.

Barton, C. M., Ullah, I., \& Mitasova, H. (2010a). Computational modeling and Neolithic socioecological dynamics: a case study from southwest Asia. American Antiquity, 75(2), 364-386.

Barton, C. M., Ullah, I. I., \& Bergin, S. (2010b). Land use, water and Mediterranean landscapes: modelling long-term dynamics of complex socio-ecological systems. Philosophical Transactions of the Royal Society A: Mathematical, Physical and Engineering Sciences, 368(1931), 5275-5297.

Barton, C. M., Riel-Salvatore, J., Anderies, J., \& Popescu, G. (2011). Modeling human ecodynamics and biocultural interactions in the late Pleistocene of western Eurasia. Human Ecology, 39, 1-21.

Beekman, C. S. (2005a). Agency, collectivities and emergence: Social theory and agent based simulations. In C. S. Beekman \& W. W. Baden (Eds.), Nonlinear Models for Archaeology and Anthropology (pp. 51-78). Aldershot, UK: Ashgate.

Beekman, C. S. (2005b). Modelling prehistoric maize agriculture as a dissipative process. In C. S. Beekman \& W. W. Baden (Eds.), Nonlinear Models for Archaeology and Anthropology (pp. 95-122). Aldershot, UK: Ashgate.

Bell, J. A. (1987). Simulation modeling in archaeology: Reflections and trends. European Journal of Operational Research, 30(3), 243-245.

Belovsky, G. E. (1987). Hunter-gatherer foraging: A linear programming approach. Journal of Anthropological Archaeology, 6(1), 29-76.

Bentley, R. A., \& Shennan, S. J. (2003). Cultural evolution and stochastic network growth. American Antiquity, 68, 459-485.

Bentley, R. A., Hahn, M. W., \& Shennan, S. J. (2004). Random drift and culture change. Proceedings of the Royal Society of London B, 271, 1443-1450.

Bentley, R. A., Lake, M. W., \& Shennan, S. J. (2005). Specialisation and wealth inequality in a model of a clustered economic network. Journal of Archaeological Science, 32, 1346-1356.

Bentley, R. A., Lipo, C., Herzog, H., \& Hahn, M. (2007). Regular rates of popular culture change reflect random copying. Evolution and Human Behavior, 28(3), 151-158.

Berger, J. F., Nuninger, L., \& van der Leeuw, S. (2007). Modeling the role of resilience in socioenvironmental co-evolution: The Rhône valley between $1000 \mathrm{BC}$ and AD 1000. In T. A. Kohler \& S. E. van der Leeuw (Eds.), The Model-Based Archaeology of Socionatural Systems (pp. 41-59). Santa Fe: School for Advanced Research Press.

Binford, L. R. (1977). For Theory Building in Archaeology. New York: Academic Press.

Biskowski, M. (1992). Cultural change, the prehistoric mind, and archaeological simulations. In P. Reilly \& S. Rahtz (Eds.), Archaeology and the Information Age (pp. 212-229). London: Routledge.

Black, S. (1978). Polynesian outliers: A study in the survial of small populations. In I. Hodder (Ed.), Simulation Studies in Archaeology (pp. 63-76). Cambridge: Cambridge University Press.

Branting, S., Wu, Y., Srikrishnan, R., \& Altaweel, M. R. (2007). SHULGI: A geospatial tool for modeling human movement and interaction. In Proceedings of Agent 2007:Complex Interaction and Social Emergence, pages 475-488, Chicago.

Brantingham, P. J. (2003). A neutral model of stone raw material procurement. American Antiquity, 68, 487-509.

Brantingham, P. J. (2006). Measuring forager mobility. Current Anthropology, 47(3), 435-459.

Brantingham, P. J (2007). A unified evolutionary model of archaeological style and function based on the price equation. American Antiquity, 72, 395-416.

Brantingham, P. J, \& Perreault, C. (2010). Detecting the effects of selection and stochastic forces in archaeological assemblages. Journal of Archaeological Science, 37(12), 3211-3225.

Campos, D., Fort, J., \& Méndez, V. (2006). Transport on fractal river networks: Application to migration fronts. Theoretical Population Biology, 69(1), 88-93.

Ch'ng, E. (2007). Using games engines for archaeological visualisation: Recreating lost worlds. In Proceedings of CGames 2007 (11th International Conference on Computer Games: AI, Animation, Mobile, Educational \& Serious Games), La Rochelle, France (2007), volume 7, pages 26-30.

Ch'ng, E., \& Stone, R. J. (2006). 3D archaeological reconstruction and visualisation: An artificial life model for determining vegetation dispersal patterns in ancient landscapes. In Proceedings of the International Conference on Computer Graphics, Imaging and Visualisation (CGIV06).

Ch'ng, E., Chapman, H., Gaffney, V., Murgatroyd, P., Gaffney, C., \& Neubauer, W. (2011). From sites to landscapes: How computing technology is shaping archaeological practice. Computer, 44(7), 40-46.

Chadwick, A. J. (1979). Settlement simulation. In C. Renfrew \& K. L. Cooke (Eds.), Transformations: Mathematical Approaches to Culture Change (pp. 237-256). New York: Academic Press.

Christiansen, J., \& Altaweel, M. (2006). Simulation of natural and social process interactions: An example from Bronze Age Mesopotamia. Social Science Computer Review, 24(2), 209-226.

Clarke, D. L. (1968). Analytical Archaeology. London: Methuen. 
Clarke, D. L. (Ed.). (1972). Models in Archaeology. London: Methuen.

Cockburn, D., Kobti, Z., \& Kohler, T. A. (2010). A reinforcement learning model for economic agent specialization. In Proceedings of the Twenty-Third International Florida Artificial Intelligence Research Society Conference (FLAIRS), pages 20-25, Menlo Park, California. AAAI Press.

Conolly, J., Colledge, S., \& Shennan, S. (2008). Founder effect, drift, and adaptive change in domestic crop use in early Neolithic Europe. Journal of Archaeological Science, 35(10), 2797-2804.

Cooke, K. L. (1979). Mathematical approaches to culture change. In C. Renfrew \& K. L. Cooke (Eds.), Transformations: Mathematical Approaches to Culture Change (pp. 45-79). New York: Academic Press.

Cooke, K. L., \& Renfrew, C. (1979). An experiment on the simulation of culture changes. In C. Renfrew \& K. L. Cooke (Eds.), Transformations: Mathematical Approaches to Culture Change (pp. 327-348). New York: Academic Press.

Cordell, L. S. (1972). Settlement Pattern Changes at Wetherill Mesa, Colorado: A Test Case for Computer Simulation in Archaeology. PhD thesis, University of California, Santa Barbara, Santa Barbara.

Costopoulos, A. (2001). Evaluating the impact of increasing memory on agent behaviour: Adaptive patterns in an agent-based simulation of subsistence. Journal of Artificial Societies and Social Simulation, 4. http://www.soc.surrey.ac.uk/JASSS/4/4/7.html.

Costopoulos, A. (2009). Simulating society. In H. Maschner, R. A. Bentley, \& C. Chippindale (Eds.), Handbook of Archaeological Theories (pp. 273-281). Lanham, Maryland: Altamira Press.

Costopoulos, A. (2010). For a theory of archaeological simulation. In A. Costopoulos \& M. Lake (Eds.), Simulating Change: Archaeology into the Twenty-First Century (pp. 21-27). Salt Lake City: University of Utah Press.

Costopoulos, A., \& Lake, M. W. (Eds.). (2010). Simulating Change: Archaeology Into the Twenty-First Century. Salt Lake City: University of Utah Press.

Cowan, J. A., Kohler, T. A., Johnson, C. D., Cooper, K., \& Bocinsky, R. K. (2012). Supply, demand, return rates, and resource depression: hunting in the Village ecodynamics world. In T. Kohler \& M. Varien (Eds.), Emergence and Collapse of Early Villages: Models of Central Mesa Verde Archaeology (pp. 129-143). Berkeley: University of California Press.

Craenen, B., Theodoropoulos, G., Suryanarayanan, V., Gaffney, V., Murgatroyd, P., \& Haldon, J. (2010). Medieval military logistics: a case for distributed agent-based simulation. In Proceedings of the $3 \mathrm{rd}$ International ICST Conference on Simulation Tools and Techniques, SIMUTools '10, pages 6:1-6:8, ICST, Brussels, Belgium. ICST. Social-Informatics and Telecommunications Engineering: Institute for Computer Sciences.

Davison, K., Dolukhanov, P., Sarson, G., \& Shukurov, A. (2006). The role of waterways in the spread of the Neolithic. Journal of Archaeological Science, 33(5), 641-652.

Davison, K., Dolukhanov, P., Sarson, G., Shukurov, A., \& Zaitseva, G. (2009). Multiple sources of the European Neolithic: Mathematical modelling constrained by radiocarbon dates. Quaternary International, 203(1), 10-18.

Dean, J. S., Gumerman, G. J., Epstein, J. M., Axtell, R. L., Swedlund, A. C., Parker, M. T., et al. (2000). Understanding Anasazi culture change through agent-based modeling. In T. A. Kohler \& G. J. Gumerman (Eds.), Dynamics in Human and Primate Societies: Agent-Based Modelling of Social and Spatial Processes (pp. 179-205). New York: Oxford Univesity Press.

Dearing, J. A., Braimoh, A. K., Reenberg, A., Turner, B. L., \& van der Leeuw, S. (2010). Complex land systems: the need for long time perspectives to assess their future. Ecology and Society, 15(4), 21.

der Velde, P. V. (1987). Post-depositional decay; a simulation. Analecta Praehistorica Leidensia, 20, $168-175$.

Donnelly, K. P. (1978). Simulations to determine the variance and edge effect of total nearest-neighbour distance. In I. Hodder (Ed.), Simulation Studies in Archaeology (pp. 91-96). Cambridge: Cambridge University Press.

Doran, J. E. (1970). Systems theory, computer simulations, and archaeology. World Archaeology, 1, $289-98$.

Doran, J. E. (1982). A computational model of socio-cultural systems and their dynamics. In C. Renfrew, M. Rowlands, \& B. Seagraves (Eds.), Theory and Explanation in Archaeology (pp. 375-388). New York: Academic Press.

Doran, J. E. (1989). Distributed AI based modelling of the emergence of social complexity. Science and Archaeology, 31, 3-11.

Doran, J. E. (1997). Distributed artificial intelligence and emergent social complexity. In S. E. van der Leeuw \& J. McGlade (Eds.), Time, Process and Structured Transformation in Archaeology (pp. 283297). London: Routledge.

Doran, J. E., \& Hodson, F. R. (1975). Mathematics and Computers in Archaeology. Edinburgh: Edinburgh University Press. 
Doran, J. E., \& Palmer, M. (1995). The EOS project: Integrating two models of Palaeolithic social change. In N. Gilbert \& R. Conte (Eds.), Artificial Societies: The Computer Simulation of Social Life (pp. 103125). London: UCL Press.

Doran, J. E., Palmer, M., Gilbert, N., \& Mellars, P. (1994). The EOS project: Modelling Upper Palaeolithic social change. In N. Gilbert \& J. Doran (Eds.), Simulating Societies (pp. 195-221). London: UCL Press.

Edmonds, M., Thomas, J., et al. (1990). Papers from the Theoretical Archaeology Group (TAG) Conference, Newcastle 1989. Scottish Archaeological Review, 7, 1-36.

Eerkens, J. W., \& Lipo, C. P. (2005). Cultural transmission, copying errors, and the generation of variation in material culture and the archaeological record. Journal of Anthropological Archaeology, 24(4), 316-334.

Eerkens, J. W., Bettinger, R. L., \& McElreath, R. (2005). Cultural transmission, phylogenetics, and the archaeological record. In C. P. Lipo, M. J. O'Brien, M. Collard, \& S. J. Shennan (Eds.), Mapping Our Ancestors: Phylogenic Methods in Anthropology and Prehistory (pp. 169-183). Somerset, NJ: Transaction Publishers.

Elliott, K., Ellman, D., \& Hodder, I. (1978). The simulation of Neolithic axe dispersal in Britain. In I. Hodder (Ed.), Simulation Studies in Archaeology (pp. 79-87). Cambridge: Cambridge University Press.

Epstein, J. M., \& Axtell, R. (1996). Growing Artificial Societies: Social Science from the Bottom Up. Washington: Brookings Press and MIT Press.

Fedotov, S., Moss, D., \& Campos, D. (2008). Stochastic model for population migration and the growth of human settlements during the Neolithic transition. Physical Review E, 78(2):026107-1-026107-7.

Ferber, J. (1999). Multi-Agent Systems: An Introduction to Distributed Artificial Intelligence. AddisonWesley, Harlow, England, english edition.

Fort, J. (2003). Population expansion in the western Pacific (Austronesia): A wave of advance model. Antiquity, 77(297), 520-530.

Fort, J. (2012). Synthesis between demic and cultural diffusion in the Neolithic transition in Europe. Proceedings of the National Academy of Sciences, 109(46), 18669-18673.

Fort, J., \& Pujol, T. (2007). Time-delayed fronts from biased random walks. New Journal of Physics, 9(7), 234.

Fort, J., Pujol, T., \& Cavalli-Sforza, L. L. (2004). Palaeolithic populations and waves of advance. Cambridge Archaeological Journal, 14(1), 53-61.

Fort, J., Pérez-Losada, J., Suñol, J., Escoda, L., \& Massaneda, J. (2008). Integro-difference equations for interacting species and the Neolithic transition. New Journal of Physics, 10(4), 043045.

Fort, J., Pujol, T., \& Linden, M. (2012). Modelling the Neolithic transition in the Near East and Europe. American Antiquity, 77(2), 203-219.

Gilbert, N. (1995). Emergence in social simulation. In N. Gilbert \& R. Conte (Eds.), Artificial Societies: The Computer Simulation of Social Life (pp. 144-156). London: U.C.L. Press.

Gilbert, N., \& Conte, R. (Eds.). (1995). Artificial Societies: The Computer Simulation of Social Life. London: UCL Press.

Gilbert, N., \& Troitzsch, K. G. (1999). Simulation for the Social Scientist. Buckingham, U.K.: Open University Press.

Griffin, A. F., \& Stanish, C. (2007). An agent-based model of prehistoric settlement patterns and political consolidation in the Lake Titicaca basin of Peru and Bolivia. Structure and Dynamics: eJournal of Anthropological and Related Sciences, 2, 1-47.

Grimm, V., \& Railsback, S. (2005). Individual-Based Modeling and Ecology. Princeton: Princeton University Press.

Grove, M. (2011). An archaeological signature of multi-level social systems: The case of the Irish Bronze Age. Journal of Anthropological Archaeology, 30(1), 44-61.

Gunn, J. (1979). Occupation frequency simulation on a broad ecotone. In C. Renfrew \& K. L. Cooke (Eds.), Transformations: Mathematical Approaches to Culture Change (pp. 257-274). New York: Academic Press.

Hahn, M. W., \& Bentley, R. A.(2003). Drift as a mechanism for cultural change: An example from baby names. Proceedings of the Royal Society of London B (Suppl.), 270, S120-S123.

Hamilton, M. J., \& Buchanan, B. (2007). Spatial gradients in Clovis-age radiocarbon dates across North America suggest rapid colonization from the north. Proceedings of the National Academy of Sciences, 104(40), 15625-15630.

Harrison Eiteljorg, I. (2004). Computing for archaeologists. In S. Schreibman, R. Siemens, \& J. Unsworth (Eds.), A Companion to Digital Humanities. Oxford: Blackwell.

Hays, D. G. (1965). Simulation: an introduction for anthropologists. In D. Hymes (Ed.), The Use of Computers in Anthropology (pp. 401-26). The Hague: Mouton. 
Heinzl, B., Auer, E., Slowacki, B., Kowarik, K., Reschreiter, H., Popper, N., et al. (2012). Physical modelling for Hallstatt archaeology. Simulation Notes Europe (SNE), 22(1), 25-32.

Hodder, I. (1978). Simulation Studies in Archaeology. Cambridge: Cambridge University Press.

Hodder, I. (1979). Simulating the growth of hierarchies. In C. Renfrew \& K. L. Cooke (Eds.), Transformations: Mathematical Approaches to Culture Change (pp. 117-144). New York: Academic Press.

Hodder, I. (1982). Symbols in Action: Ethnoarchaeological Studies of Material Culture. Cambridge: Cambridge University Press.

Hodder, I., \& Orton, C. (1976). Spatial Analysis in Archaeology. Cambridge: Cambridge University Press.

Holland, J. H. (1995). Hidden order: how adaptation builds complexity. Reading, MA: Addison-Wesley.

Holland, J. H. (1998). Emergence: From Chaos to Order. Oxford: Oxford University Press.

Hosler, D., Sabloff, J. A., \& Runge, D. (1977). Simulation model development: A case study of Classical Maya collapse. In L. H. Gunderson, C. S. H. and Light, S. S., editors, Social Processes in Maya Prehistory, pages 552-590. London: Academic Press.

Innis, G. S. (1972). Simulation of ill-defined systems, some problems and progress. Simulation, 19, 33-36.

Janssen, M. A., \& Anderies, J. M. (2007). Stylized models to analyze robustness of irrigation systems. In T. A. Kohler \& S. E. van der Leeuw (Eds.), The Model-Based Archaeology of Socionatural Systems (pp. 157-174). Santa Fe: School for Advanced Research Press.

Johnson, C. D., Kohler, T. A., \& Cowan, J. (2005). Modeling historical ecology, thinking about contemporary systems. American Anthropologist, 107(1), 96-107.

Kachel, A. F., Premo, L., \& Hublin, J.-J. (2011a). Grandmothering and natural selection. Proceedings of the Royal Society B: Biological Sciences, 278(1704), 384-391.

Kachel, A. F., Premo, L., \& Hublin, J.-J. (2011b). Grandmothering and natural selection revisited. Proceedings of the Royal Society B: Biological Sciences, 278(1714), 1939-1941.

Kachel, A. F., Premo, L., \& Hublin, J.-J. (2011c). Modeling the effects of weaning age on length of female reproductive period: Implications for the evolution of human life history. American Journal of Human Biology, 23(4), 479-487.

Kirch, P. V., Chadwick, O. A., Tuljapurkar, S., Ladefoged, T., Graves, M., Hotchkiss, S., et al. (2007). Human ecodynamics in the Hawaiian ecosystem, from 1200 to $200 \mathrm{yr}$ BP. In T. A. Kohler \& S. E. van der Leeuw (Eds.), The Model-Based Archaeology of Socionatural Systems (pp. 121-140). Santa Fe: School for Advanced Research Press.

Knappett, C., Evans, T., \& Rivers, R. (2011). The Theran eruption and Minoan palatial collapse: new interpretations gained from modelling the maritime network. Antiquity, 85(329), 1008-1023.

Kohler, T. A. (2000). Putting social sciences together again: An introduction to the volume. In T. A. Kohler \& G. J. Gumerman (Eds.), Dynamics in Human and Primate Societies: Agent-Based Modelling of Social and Spatial Processes (pp. 1-44). New York: Oxford University Press.

Kohler, T., \& Carr, E. (1997). Swarm-based modelling of prehistoric settlement systems in southwestern North America. In Johnson, I. and North, M., editors, Archaeological Applications of GIS: Proceedings of Colloquium II, UISPP XIIIth Congress, Forli, Italy, September 1996, volume 5 of Sydney University Archaeological Methods Series. Archaeological Computing Laboratory, Sydney. CD-ROM.

Kohler, T. A., \& Gumerman, G. J. (Eds.). (2000). Dynamics in Human and Primate Societies: Agent Based Modeling of Social and Spatial Processes. Oxford: Oxford University Press.

Kohler, T. A., \& van der Leeuw, S. E. (2007). Introduction: Historical socionatural systems and models. In T. A. Kohler \& S. E. van der Leeuw (Eds.), The Model-Based Archaeology of Socionatural Systems (pp. 1-12). Santa Fe: School for Advanced Research Press.

Kohler, T. A., \& Varien, M. D. (2012). Emergence and collapse of early villages in the central Mesa Verde: An introduction. In Emergence and Collapse of Early Villages in the Central Mesa Verde: Models of Central Mesa Verde Archaeology (pp. 1-14). Berkeley: University of California Press.

Kohler, T. A., Kresl, J., West, C. V., Carr, E., \& Wilshusen, R. H. (2000). Be there then: A modeling approach to settlement determinants and spatial efficiency among Late Ancestral Pueblo populations of the Mesa Verde region, U.S. Southwest. In T. A. Kohler \& G. J. Gumerman (Eds.), Dynamics in Human and Primate Societies (pp. 145-178). New York: Oxford University Press.

Kohler, T. A., Gumerman, G. J., \& Reynolds, R. G. (2005). Simulating ancient societies. Scientific American, 293, 76-84.

Kohler, T. A., Johnson, C. D., Varien, M., Ortman, S., Reynolds, R., Kobti, Z., et al. (2007). Settlement ecodynamics in the prehispanic central Mesa Verde region. In T. A. Kohler \& S. E. van der Leeuw (Eds.), Model-Based Archaeology of Socionatural Systems (pp. 61-104). Santa Fe, NM: SAR Press.

Kohler, T. A., Bocinsky, R. K., Cockburn, D., Crabtree, S. A., Varien, M. D., Kolm, K. E., et al. (2012a). Modelling prehispanic Pueblo societies in their ecosystems. Ecological Modelling, 241, 30-41. 
Kohler, T. A., Cockburn, D., Hooper, P. L., Bocinsky, R. K., \& Kobti, Z. (2012b). The coevolution of group size and leadership: an agent-based public goods model for prehispanic Pueblo societies. Advances in Complex Systems, $15(1$ \& 2):1150007-1-1150007-29.

Lake, M. W. (1996). Archaeological inference and the explanation of hominid evolution. In J. Steele \& S. Shennan (Eds.), The Archaeology of Human Ancestry: Power, Sex and Tradition (pp. 184-206). London: Routledge.

Lake, M. W. (1997). Darwinian archaeology: an 'ism' for our times? (review of P. A. Teltser (ed.), 1995, 'Evolutionary Archaeology: Methodological Issues', and H. D. G. Maschner (ed.), 1996, 'Darwinian Archaeologies'). Antiquity, 71:1086-1088.

Lake, M. W. (2000a). MAGICAL computer simulation of Mesolithic foraging. In T. A. Kohler \& G. J. Gumerman (Eds.), Dynamics in Human and Primate Societies: Agent-Based Modelling of Social and Spatial Processes (pp. 107-143). New York: Oxford University Press.

Lake, M. W. (2000b). MAGICAL computer simulation of Mesolithic foraging on Islay. In S. J. Mithen (Ed.), Hunter-Gatherer Landscape Archaeology: The Southern Hebrides Mesolithic Project, 1988-98, volume 2: Archaeological Fieldwork on Colonsay, Computer Modelling, Experimental Archaeology, and Final Interpretations (pp. 465-495). Cambridge: The McDonald Institute for Archaeological Research.

Lake, M. W. (2001a). Numerical modelling in archaeology. In D. R. Brothwell \& A. M. Pollard (Eds.), Handbook of Archaeological Sciences (pp. 723-732). Chichester: John Wiley \& Sons.

Lake, M. W. (2001b). The use of pedestrian modelling in archaeology, with an example from the study of cultural learning. Environment and Planning B: Planning and Design, 28, 385-403.

Lake, M. W. (2004). Being in a simulacrum: Electronic agency. In A. Gardner (Ed.), Agency Uncovered: Archaeological Perspectives on Social Agency, Power and Being Human (pp. 191-209). London: UCL Press.

Lake, M. W. (2008). Interpreting the record / computer simulation modeling. In D. Pearsall (Ed.), Encyclopedia of Archaeology (pp. 1034-1040). Amsterdam: Elsevier/Academic Press.

Lake, M. W. (2010). The uncertain future of simulating the past. In A. Costopoulos \& M. Lake (Eds.), Simulating Change: Archaeology into the Twenty-First Century (pp. 12-20). Salt Lake City: University of Utah Press.

Lake, M. (2014). Explaining the past with ABM: On modelling philosophy. In G. Wurzer, K. Kowarik, \& H. Reschreiter (Eds.), Agent-based Modeling and Archaeology. Berlin: Springer (in press).

Lake, M. W., \& Crema, E. R. (2012). The cultural evolution of adaptive-trait diversity when resources are uncertain and finite. Advances in Complex Systems, 15(1 \& 2):1150013-1-1150013-19.

Lansing, J. S. (2000). Anti-chaos, common property, and the emergence of cooperation. In T. A. Kohler \& G. J. Gumerman (Eds.), Dynamics in Human and Primate Societies: Agent-Based Modelling of Social and Spatial Processes (pp. 207-224). New York: Oxford Univesity Press.

Lansing, S. J., \& Kremer, J. N. (1993). Emergent properties of Balinese water temple networks: Coadaptation on a rugged fitness landcape. In C. G. Langton (Ed.), Artificial Life III, volume XVII of Santa Fe Institute Series in the Sciences of Complexity (pp. 201-224). Reading, MA: Addison-Wesley.

Levison, M., Ward, R., \& Webb, J. (1973). The Settlement of Polynesia: A Computer Simulation. Minneapolis: University of Minnesota Press.

Lock, G. (2003). Using Computers in Archaeology: Towards Virtual Pasts. London: Routledge.

Lockyear, K. (1991). Simulating coin hoard formation. In K. Lockyear \& S. Rahtz (Eds.), Computer Applications and Quantitative Methods in Archaeology 1990, number 565 in British Archaeological Reports International Series (pp. 195-206). Oxford: Tempvs Reparatvm.

McClure, S., Barton, C. M., \& Jochim, M. (2009). Human behavioral ecology and climate change during the transition to agriculture in Valencia, eastern Spain. Journal of Anthropological Research, 65(2), 253-269.

McGlade, J. (1995). Archaeology and the ecodynamics of human-modified landscapes. Antiquity, 69, 113-132.

McGlade, J. (1997a). GIS and integrated archaeological knowledge systems. In Johnson, I. and North, M., editors, Archaeological Applications of GIS: Proceedings of Colloquium II, UISPP XIIIth Congress, Forli, Italy, September 1996, volume 5 of Sydney University Archaeological Methods Series. Archaeological Computing Laboratory, Sydney. CD-ROM.

McGlade, J. (1997b). The limits of social control: Coherence and chaos in a prestige-goods economy. In S. E. van der Leeuw \& J. McGlade (Eds.), Time, Process and Structured Transformation in Archaeology (pp. 298-330). London: Routledge.

McGlade, J. (2005). Systems and simulacra: Modeling, simulation, and archaeological interpretation. In H. D. G. Maschner \& C. Chippindale (Eds.), Handbook of archaeological methods (pp. 554-602). Oxford: Altamira Press.

McPherron, S., \& Dibble, H. L. (2001). Using Computers In Archaeology: A Practical Guide. McGraw Hill. 
Mesoudi, A., \& Lycett, S. J. (2009). Random copying, frequency-dependent copying and culture change. Evolution and Human Behavior, 30(1), 41-48.

Minsky, M., \& Papert, S. (1969). Perceptrons: an introduction to computational geometry. Cambridge, MA: MIT Press.

Mithen, S. J. (1986). The application of Leslie Matrix models in archaeology. Science in Archaeology, 28, 24-31.

Mithen, S. J. (1988a). Simulation as a methodological tool: Inferring hunting goals from faunal assemblages. In Ruggles, C. L. N. and Rahtz, S. P. Q., editors, Computer and Quantitative Methods in Archaeology 1987, number 393 in International Series, pages 119-137. British Archaeological Reports.

Mithen, S. J. (1988b). To hunt or to paint: animals and art in the Upper Palaeolithic. Man (N.S.), 23, 671695.

Mithen, S. J. (1989). Modeling hunter-gatherer decision making: Complementing optimal foraging theory. Human Ecology, 17, 59-83.

Mithen, S. J. (1990). Thoughtful Foragers: A Study of Prehistoric Decision Making. Cambridge: Cambridge University Press.

Mithen, S. J. (1994). Simulating prehistoric hunter-gatherers. In N. Gilbert \& J. Doran (Eds.), Simulating Societies: The Computer Simulation of Social Phenomena (pp. 165-193). London: UCL Press.

Mithen, S. J. (1997). Simulating mammoth hunting and extinctions: Implications for North America. In S. E. van der Leeuw \& J. McGlade (Eds.), Time, Process and Structured Transformations in Archaeology (pp. 177-215). London: Routledge.

Mithen, S. J, \& Reed, M. (2002). Stepping out: A computer simulation of hominid dispersal from Africa. Journal of Human Evolution, 43, 433-462.

Mosimann, J. E., \& Martin, P. S. (1975). Simulating overkill by palaeoindians. American Scientist, 63, $304-313$.

Murgatroyd, P., Craenen, B., Theodoropoulos, G., Gaffney, V., \& Haldon, J. (2011). Modelling Medieval military logistics: an agent-based simulation of a Byzantine army on the march. Computational \& Mathematical Organization Theory, 18, 488-506.

Neiman, F. D. (1995). Stylistic variation in evolutionary perspective: inferences from decorative diversity and interassemblage distance in Illinois Woodland ceramic assemblages. American Antiquity, 60(1), 7-36.

Nikitas, P., \& Nikita, E. (2005). A study of hominin dispersal out of Africa using computer simulations. Journal of Human Evolution, 49, 602-617.

O'Shea, J. M. (1978). The simulation of Pawnee site development. In I. Hodder (Ed.), Simulation studies in archaeology (pp. 39-46). Cambridge: Cambridge University Press.

O'Sullivan, D., \& Haklay, M. (2000). Agent-based models and individualism: is the world agent-based? Environment and Planning A, 32, 1409-1425.

Orton, C. (1973). The tactical use of models in archaeology - the SHERD project. In C. Renfrew (Ed.), The explanation of culture change (pp. 137-9). London: Duckworth.

Orton, C. (1982). Computer simulation experiments to assess the performance of measures of quantity of pottery. World Archaeology, 14, 1-19.

Patterson, M., Sarson, G., Sarson, H., \& Shukurov, A. (2010). Modelling the Neolithic transition in a heterogeneous environment. Journal of Archaeological Science, 37(11), 2929-2937.

Pepper, J. W., \& Smuts, B. B. (2000). The evolution of cooperation in an ecological context: an agent-based model. In T. A. Kohler \& G. J. Gumerman (Eds.), Dynamics in human and primate societies: agentbased modelling of social and spatial processes (pp. 45-76). New York: Oxford Univesity Press.

Pérez-Losada, J., \& Fort, J. (2011). Spatial dimensions increase the effect of cultural drift. Journal of Archaeological Science, 38(6), 1294-1299.

Pinhasi, R., Fort, J., \& Ammerman, A. J. (2005). Tracing the origin and spread of agriculture in Europe. PLoS biology, 3(12), e410.

Potts, R. (1988). Early Hominid Activities at Olduvai. New York: Aldine de Gruyter.

Powell, A., Shennan, S. J., \& Thomas, M. G. (2009). Late Pleistocene demography and the appearance of modern human behavior. Science, 324, 1298-1301.

Powell, A., Shennan, S. J., \& Thomas, M. G. (2010). Demography and variation in the accumulation of culturally inherited skills. In M. J. O'Brien \& S. J. Shennan (Eds.), Innovation in cultural systems: contributions from evolutionary anthropology, Vienna Series in Theoretical Biology (pp. 137-160). Cambridge, MA: MIT Press.

Premo, L. S. (2005). Patchiness and prosociality: an agent-based model of Plio/Pleistocene hominid food sharing. In P. Davidsson, K. Takadama, \& B. Logan (Eds.), Multi-agent andmulti-agent-based simulation, volume 3415 of Lecture Notes in Artificial Intelligence (pp. 210-224). Berlin: Springer.

Premo, L. S. (2006a). Agent-based models as behavioral laboratories for evolutionary anthropological research. Arizona Anthropologist, 17, 91-113. 
Premo, L. S. (2006b). Patchiness and prosociality: modelling the evolution and Archaeology of PlioPleistocene hominin food sharing. Ph.D. thesis, University of Arizona.

Premo, L. S. (2007). Exploratory agent-based models: Towards an experimental ethnoarchaeology. In J. T. Clark \& E. M. Hagemeister (Eds.), Digital discovery: exploring new frontiers in human heritage. CAA 2006. Computer applications and quantitative methods in archaeology (pp. 29-36). Budapest: Archeolingua Press.

Premo, L. S. (2008). Exploring behavioral terra incognita with archaeological agent-based models. In B. Frischer \& A. Dakouri-Hild (Eds.), In Beyond Illustration: 2D and 3D Technologies as Tools of Discovery in Archaeology, British Archaeological Reports International Series (pp. 46-138). Oxford: ArchaeoPress.

Premo, L. S. (2010). Equifinality and explanation: the role of agent-based modeling in postpositivist archaeology. In A. Costopoulos \& M. Lake (Eds.), Simulating change: archaeology into the twentyfirst century (pp. 28-37). Salt Lake City: University of Utah Press.

Premo, L. S. (2012a). Local extinctions, connectedness, and cultural evolution in structured populations. Advances in Complex Systems, 15(1\&2):1150002-1-1150002-18.

Premo, L. S. (2012b). The shift to a predominantly logistical mobility strategy can inhibit rather than enhance forager interaction. Human Ecology, 40, 647-649.

Premo, L. S. (2012c). Hitchhiker's guide to genetic diversity in socially structured populations. Current Zoology, 58, 287-297.

Premo, L. S., \& Hublin, J.-J. (2009). Culture, population structure, and low genetic diversity in Pleistocene hominins. Proceedings of the National Academy of Science, USA, 106(1), 33-37.

Premo, L. S., \& Kuhn, S. L. (2010). Modeling effects of local extinctions on culture change and diversity in the Paleolithic. PLoS One, 5(12), e15582.

Premo, L. S., \& Scholnick, J. B. (2011). The spatial scale of social learning affects cultural diversity. American Antiquity, 76(1), 163-176.

Premo, L. S., Murphy, J. T., Scholnick, J. B., Gabler, B. M., \& Beaver, J. M. (2005). Making a case for agent-based modeling. Society for Archaeological Sciences Bulletin, 28(3), 11-13.

Railsback, S. F., \& Grimm, V. (2012). Agent-based and individual-based modeling: a practical introduction. Princeton: Princeton University Press.

Renfrew, C. (1978). Trajectory discontinuity and morphogenesis: the implications of catastrophe theory for archaeology. American Antiquity, 43, 203-222.

Renfrew, C. (1979a). System collapse as social transformation. In C. Renfrew \& K. L. Cooke (Eds.), Transformations: mathematical approaches to culture change (pp. 481-506). New York: Academic Press.

Renfrew, C. (1979b). Transformations. In C. Renfrew \& K. L. Cooke (Eds.), Transformations: mathematical approaches to culture change (pp. 3-44). New York: Academic Press.

Renfrew, A. C. (1982). Towards an Archaeology of Mind (Inaugral Lecture to the University of Cambridge). Cambridge: Cambridge University Press.

Renfrew, C. (1994). Towards a cognitive archaeology. In C. Renfrew \& E. B. W. Zubrow (Eds.), The ancient mind: elements of a cognitive archaeology (pp. 3-12). Cambridge: Cambridge University Press.

Renfrew, C., \& Cooke, K. L. (Eds.). (1979). Transformations: mathematical approaches to culture change. New York: Academic Press.

Renfrew, C., Rowlands, M., \& Seagraves, B. (Eds.). (1982). Theory and explanation in archaeology. New York: Academic Press.

Reynolds, R. G. (1986). An adaptive computer model for the evolution of plant collecting and early agriculture in the eastern valley of Oaxaca. In K. V. Flannery (Ed.), Guila Naquitz: Archaic foraging and early agriculture in Oaxaca, Mexico (pp. 439-507). London: Academic Press.

Reynolds, R. G. (1987). A production system model of hunter-gatherer resource scheduling adaptations. European Journal of Operational Research, 30(3), 237-239.

Reynolds, R. G. (1997). Why does cultural evolution proceed at a faster rate than biological evolution? In S. E. van der Leeuw \& J. McGlade (Eds.), Time, Process and Structured Transformation in Archaeology (pp. 269-282). London: Routledge.

Reynolds, R. G., \& Zeigler, B. P. (1979). A formal mathematical model for the operation of consensus based hunting-gathering bands. In A. C. Renfrew \& K. Cooke (Eds.), Transformations: mathematical approaches to culture change. New York: Academic Press.

Reynolds, R. G., Whallon, R., Ali, M. Z., \& Zadegan, B. M. (2010). Agent-based model of early cultural evolution. In A. Costopoulos \& M. Lake (Eds.), Simulating change: archaeology into the twenty-first century (pp. 38-52). Salt Lake City: University of Utah Press.

Richards, J. D. (1998). Recent trends in computer applications in archaeology. Journal of Archaeological Research, 6(4), 331-382. 
Rubio-Campillo, X., Marìa Cela, J., \& Hernàndez Cardona, F. (2011). Simulating archaeologists? Using agentbased modelling to improve battlefield excavations. Journal of Archaeological Science, 39, 347-356.

Rubio-Campillo, X., Cela, J., \& Cardona, F. (2013). The development of new infantry tactics during the early eighteenth century: a computer simulation approach to modern military history. Journal of Simulation, 7, 170-182.

Sabloff, J. A. (Ed.). (1981). Simulations in archaeology. Albuquerque: University of New Mexico Press.

Schuster, H. G. (1988). Deterministic Chaos. New York: VCH Publishers.

Shanks, M., \& Tilley, C. (1987). Social theory and archaeology. Cambridge: Polity Press.

Shennan, S. J. (2008). Evolution in archaeology. Annual Review of Anthropology, 37, 75-91.

Skyrms, B. (2000). Evolution of inference. In T. A. Kohler \& G. J. Gumerman (Eds.), Dynamics in human and primate societies: agent-based modelling of social and spatial processes (pp. 77-88). New York: Oxford University Press.

Smith, E. A., \& Choi, J.-K. (2007). The emergence of inequality in small-scale societies: simple scenarios and agent-based simulations. In T. A. Kohler \& S. E. van der Leeuw (Eds.), The model-based archaeology of socionatural systems (pp. 105-120). Santa Fe: School for Advanced Research Press.

Steele, J. (1994). Communication networks and dispersal patterns in human evolution: a simple simulation model. World Archaeology, 26, 126-143.

Steele, J. (2009). Human dispersals: mathematical models and the archaeological record. Human Biology, $81,121-140$.

Steele, J., Sluckin, T., \& Denholm, D. (1996). Simulating hunter-gatherer colonization of the Americas. In H. Kamermans \& K. Fennema (Eds.), Interfacing the Past, number 28 in Analecta Praehistorica Leidensia (pp. 223-227). Leiden: Institute of Prehistory, University of Leiden.

Steele, J., Adams, J., \& Sluckin, T. (1998). Modelling Palaeoindian dispersals. World Archaeology, 30, $286-305$

Surovell, T., \& Brantingham, P. (2007). A note on the use of temporal frequency distributions in studies of prehistoric demography. Journal of Archaeological Science, 34(11), 1868-1877.

te Boekhorst, I. J., \& Hemelrijk, C. K. (2000). Nonlinear and synthetic models for primate societies. In T. A. Kohler \& G. J. Gumerman (Eds.), Dynamics in human and primate societies: agent-based modelling of social and spatial processes (pp. 19-44). New York: Oxford University Press.

Thomas, D. H. (1972). A computer simulation model of Great Basin Shoshonean subsistance and settlement. In D. L. Clarke (Ed.), Models in archaeology (pp. 671-704). London: Methuen.

Thomas, J. (1991). The hollow men? A reply to Steven Mithen. Proceedings of the Prehistoric Society, 57, 15-20.

Vaesen, K. (2012). Cumulative cultural evolution and demography. PloS one, 7(7), e40989.

van der Leeuw, S. E., \& McGlade, J. (1997a). Introduction: archaeology and non-linear dynamics-new approaches to long-term change. In S. E. van der Leeuw \& J. McGlade (Eds.), Time, process and structured transformation in archaeology (pp. 1-31). London: Routledge.

van der Leeuw, S. E., \& McGlade, J. (1997b). Structural change and bifurcation in urban evolution: a non linear dynamical perspective. In S. E. van der Leeuw \& J. McGlade (Eds.), Time, process and structured transformation in archaeology (pp. 331-372). London: Routledge.

van der Leeuw, S. E., \& McGlade, J. (Eds.). (1997c). Time, process and structured transformation in archaeology. London: Routledge.

van der Leeuw, S. E., \& Redman, C. L. (2002). Placing archaeology at the center of socio-natural studies. American Antiquity, 67(4), 597-605.

Verhagen, P., \& McGlade, J. (1997). Spatialising dynamical modelling: A new opportunity for GIS. In Johnson, I. and North, M., editors, Archaeological Applications of GIS: Proceedings of Colloquium II, UISPP XIIIth Congress, Forli, Italy, September 1996, volume 5 of Sydney University Archaeological Methods Series. Archaeological Computing Laboratory, Sydney. CD-ROM.

Waldrop, M. (1992). Complexity: the emerging science at the edge of order and chaos. New York: Simon \& Schuster. Westervelt, J. D. (2002). Geographic information systems and agent-based modelling. In H. R. Gimblett (Ed.), Integrating geographic information systems and agent-based modeling techniques for simulating social and ecological processes (pp. 83-104). Oxford: Oxford University Press.

Whallon, R. (1972). The computer in archaeology: a critical survey. Computers and the Humanities, 7, $29-45$.

Wilkinson, T., Christiansen, J., Ur, J., Widell, M., \& Altaweel, M. (2007a). Urbanization within a dynamic environment: modeling Bronze Age communities in upper Mesopotamia. American Anthropologist, 109(1), 52-68.

Wilkinson, T. J., Gibson, M., Christiansen, J. H., Widell, M., Schloen, D., Kouchoukos, N., et al. (2007b). Modeling settlement systems in a dynamic environment: case studies from Mesopotamia. In T. A. Kohler \& S. E. van der Leeuw (Eds.), The model-based archaeology of socionatural systems (pp. 175208). Santa Fe: School for Advanced Research Press. 
Wobst, H. M. (1974). Boundary conditions for Palaeolithic social systems: a simulation approach. American Antiquity, 39, 147-178.

Wobst, H. M. (2010). Discussant's comments, Computer Simulation Symposium, Society for American Archaeology. In A. Costopoulos \& M. Lake (Eds.), Simulating change: archaeology into the twentyfirst century (pp. 9-11). Salt Lake City: University of Utah Press.

Wolfram, S. (1986). Theory and applications of cellular automata. Singapore: World Scientific.

Wren, C. D., Zue, J. X., Costopoulos, A., \& Burke, A. (2013). The role of spatial foresight on models of hominin dispersal. Journal of Human Evolution. Under review.

Wright, H. T. (2000). Agent-based modeling of small-scale societies: state of the art and future prospects. In T. A. Kohler \& G. J. Gumerman (Eds.), Dynamics in human and primate societies: agent-based modelling of social and spatial processes (pp. 373-386). New York: Oxford University Press.

Wright, H. T. (2007). Progress in cultural modelling. In T. A. Kohler \& S. E. van der Leeuw (Eds.), The model-based archaeology of socionatural systems (pp. 229-232). Santa Fe: School for Advanced Research Press.

Wright, H. T., \& Zeder, M. (1977). The simulation of a linear exchange system under equilibrium conditions. In T. K. Earle \& J. E. Ericson (Eds.), Exchange systems in prehistory (pp. 233-253). New York: Academic Press.

Xue, J. Z., Costopoulos, A., \& Guichard, F. (2011). Choosing fitness-enhancing innovations can be detrimental under fluctuating environments. PloS one, 6(11), e26770.

Yiannouli, E., \& Mithen, S. J. (1986). The real and the random architecture of Siphnos: analysing house plans using simulation. Archaeological Review from Cambridge, 5, 167-180.

Yorston, R., Gaffney, V., \& Reynolds, P. (1990). Simulation of artefact movement due to cultivation. Journal of Archaeological Science, 17(1), 67-83.

Young, D. A., \& Bettinger, R. L. (1995). Simulating the global human expansion in the Late Pleistocene. Journal of Archaeological Science, 22, 89-92.

Zeeman, E. C. (Ed.). (1977). Readings in catastrophe theory. Reading, MA: Addison-Wesley.

Zimmerman, L. J. (1977). Prehistoric locational behaviour: a computer simulation (Number 10 in Reports of the State Archaeologist of Iowa). Iowa: University of Iowa Press.

Zubrow, E. (1971). Carrying capacity and dynamic equilibrium in the prehistoric Southwest. American Antiquity, 36, 127-138.

Zubrow, E. (1981). Simulation as a heuristic device in archaeology. In J. A. Sabloff (Ed.), Simulations in archaeology (pp. 143-188). Albuquerque: University of New Mexico Press.

Zubrow, E. (1997). Clusters of death, pockets of survival: dynamic modelling and GIS. In S. E. van der Leeuw \& J. McGlade (Eds.), Time, process and structured transformation in archaeology (pp. 216253). London: Routledge. 